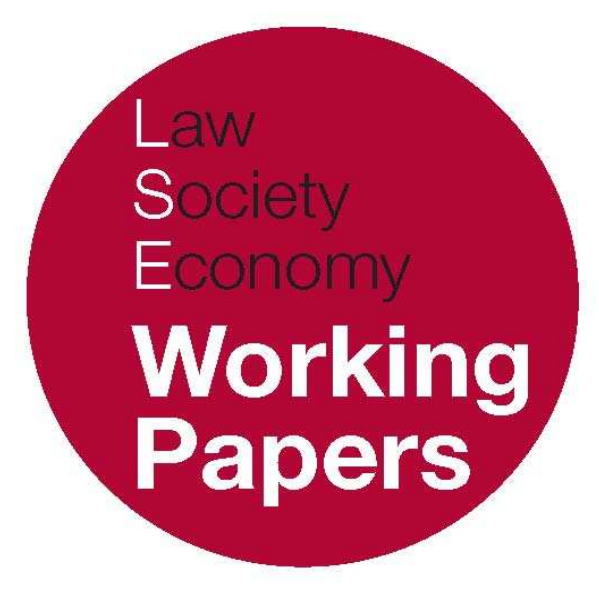

\title{
After Copenhagen: \\ The Impossibility of Carbon Trading
}

\author{
David Campbell, Matthias Klaes, \\ and Christopher Bignell
}

\section{LSE Law, Society and Economy Working Papers 22/2010 \\ London School of Economics and Political Science}

Law Department

This paper can be downloaded without charge from LSE Law, Society and Economy Working Papers at: www.lse.ac.uk/collections/law/wps/wps.htm and the Social Sciences Research Network electronic library at: http://ssrn.com/abstract=1719643.

(C) David Campbell, Matthias Klaes, and Christopher Bignell. Users may download and/or print one copy to facilitate their private study or for non-commercial research. Users may not engage in further distribution of this material or use it for any profit-making activities or any other form of commercial gain. 


\title{
After Copenhagen: The Impossibility of Carbon Trading
}

\section{David Campbell, Matthias Klaes, and Christopher Bignell *}

\begin{abstract}
The attempt to develop international cap and trade markets for anthropogenic greenhouse gas emissions, ultimately aiming to determine a global price for carbon, is the most extensive attempt ever made to use market-mimicking mechanisms to deal with an environmental externality. Addressed to the problem of climate change, it is an exercise in the adjustment of the social welfare function on a global scale, and it envisages expenditures which will run into trillions of dollars. Focusing on the operation of the Clean Development Mechanism, the most important of the three flexible mechanisms for carbon trade established under the Kyoto Protocol, it will be argued that carbon trading which will reduce emissions in line with any of the targets set for avoiding dangerous anthropological interference is impossible. Climate change negotiations have completely failed to place a cap on global
\end{abstract}

* David Campbell, Professor, Durham Law School, Durham University; Matthias Klaes, Professor and Head of the Keele Management School, Keele University; Christopher Bignell, JD Student, Cardozo School of Law, Yeshiva University, New York, USA.

We are grateful to the Cardozo School of Law and to the Institute of Commercial and Company Law, Durham Law School, for financial support of Mr Bignell's work on this paper. Campbell has presented earlier versions of this paper to the School of Law, University of Lucerne, Switzerland; the School of Law, La Trobe University; the Cardozo School of Law; the Syracuse University College of Law, New York, USA; the Interdisciplinary Centre of the Social Sciences, Sheffield University; the Faculty of Law, University of Hong Kong; the Hong Kong Forum; the TC Bierne School of Law; the Faculty of Law, University of Auckland; the School of Law, Murdoch University; and the Department of Law, LSE. We are grateful for comments made at all these presentations, and to Ian Abell, James Devenney, Jo Goodie, David Kershaw, Bob Lee, Sol Picciotto, Tom Poole, Joanne Scott, Gary Wickham, and an anonymous reviewer for particular help. The final, published version of the paper is to appear in The University of Queensland Law Journal.

In 2009, a planning application ultimately intended to lead to the construction of a wind farm less than two miles from Campbell's home was lodged with Durham County Council, to which Campbell and his wife object.

Our title is a play on a W.D. Nordhaus, 'After Kyoto: Alternative Mechanisms to Control Global Warming' (2006) 96 American Economics Review (Papers and Proceedings), 31. 
emissions; indeed, they have given a legal permission to increase them. Reflecting the fatal shortcomings of the Kyoto Protocol, the operation of the CDM so far has not merely failed to secure reductions, but in all likelihood has actually increased the absolute level of emissions.

\section{INTRODUCTION}

Described as a passage 'From Hopenhagen to Fiascohagen in 12 dire days' by $\mathrm{Mr}$ Jonathan Porritt, one of the UK's most prominent environmental activists, ${ }^{1}$ the UN Climate Change Conference held in Copenhagen from 7-18 December 2009 $(\mathrm{COP} 15)^{2}$ is widely held to have been a failure. The Conference would have ended entirely without agreement had not a self-selecting group of five countries acted outside agreed COP15 negotiating procedures, ${ }^{3}$ indeed initially without UN involvement at all, to produce The Copenhagen Accord (CA), ${ }^{4}$ a very general document of no legal status, ${ }^{5}$ to which no country, certainly not those which initially produced it, has made a significant commitment.

In this paper we will analyse the most important aspect of this failure for understanding current developments in the scale, scope, and technique of international regulatory theory and practice. The environmental economic intervention that has now met with failure in Copenhagen, 'carbon trading' under the 1997 Kyoto Protocol (KP), ${ }^{6}$ is the first major exercise in what we will call the 'new global welfare economics', in which the welfare economics that has dominated national economic and social policy in the twentieth century has been extended to a global scope and scale. As every country's anthropogenic greenhouse gas (GHG) emissions contribute to the atmospheric concentration of

\footnotetext{
${ }^{1}$ J. Porritt, 'Selling a Low-carbon Life Just Got Harder' The Times (21 December 2009), at http://www.timesonline.co.uk/tol/comment/columnists/guest_contributors/article6963387.ece.

2 This acronym denotes that Copenhagen is the fifth meeting of the Conference of the Parties to the UN Framework Convention on Climate Change (UNFCCC) 9 May 1992, 1771 UNTS 107, entered into force 21

March 1994, at http://unfccc.int/resource/docs/convkp/conveng.pdf. Since COP11 in Montreal in 2005, COPs have been held in conjunction with Meetings of the Parties to the Kyoto Protocol. COP15 was MOP5, and so it is sometimes referred to as COP15/MOP5 or CMP15, ie the Conference of the Parties serving as the Meeting of the Parties.

3 These were the USA plus the 'BASIC' bloc formed by Brazil, South Africa (Afrique du Sud), India, and the PRC. This bloc seems to be developing a common policy towards climate change after the CA. K Mackenzie, 'Statement by the BASIC Ministers' Financial Times Energy Source Blogs (25 January 2010), at http://blogs.ft.com/energy-source/2010/01/25/statement-by-the-basic-ministers/.

${ }^{4}$ COP15, Draft Decision -/CP15: The Copenhagen Accord (FCCC/CP/2009/1.7, 18 December 2009), at http://unfccc.int/resource/docs/2009/cop15/eng/107.pdf.

${ }^{5}$ Executive Secretary of the UNFCCC Secretariat, Clarification Relating to the Notification of 18 January 2010 (FCCC/DBO/drl, 25 January 2010), at

http://unfccc.int/files/parties_and_observers/notifications/application/pdf/100125_noti_clarification.p df.

${ }^{6}$ Kyoto Protocol to the United Nations Framework Convention on Climate Change, December 1997, 2303 UNTS

148, entered into force 16 February 2005, at http://unfccc.int/resource/docs/convkp/kpeng.pdf.
} 
GHG, ${ }^{7}$ of its technological nature global warming is the paradigm case of an 'international' or 'global externality', and it has called for, and received, a global response based on the 1992 UN Framework Convention on Climate Change (UNFCCC). ${ }^{8}$ But though a welfare economic intervention which is in one sense familiar, carbon trading must be placed in the context of the changes to national regulatory technique made in response to the neo-classical revolution of the 1970s, in which command and control has been largely replaced by market-mimicking forms of regulation which are traced to the work of Ronald Coase. The new global welfare economics conceive of carbon trading as a global market-mimicking response to a global externality.

Our analysis of this major development in regulation leads to a very disquieting conclusion. Carbon trading which will lead to a reduction in global GHG emissions is, and has been from the outset, an impossibility. As COP15 began to make clear, the first major exercise in the new global welfare economics was bound to be a complete failure, and continued attempts to implement it are irrational. Certain reflections on how a major policy so completely defective can be adopted will be put forward.

\section{THE KP AND THE CLEAN DEVELOPMENT MECHANISM}

The explanation of environmental pollution as an externality is conterminous with the history of modern welfare economics. Pigou's first example of the negative externality in The Economics of Welfare was factory smoke, ${ }^{9}$ and he remained concerned with environmental matters throughout his life. A famous and characteristic work in the Pigouvian tradition, Kapp's, The Social Costs of Private Enterprise, used the externality argument to show pollution to be an immense social cost in the capitalist countries. ${ }^{10}$ In this tradition, but carrying it on to an actually global scope and scale, climate change takes its place as, in the words of the Stern Review (SR), the influential review of climate change led by Sir Nicholas Stern for

\footnotetext{
${ }^{7}$ By far the most important gas causing the 'greenhouse effect' is water vapour, but, of course, the bulk of water vapour is not produced by human activity. A proper understanding of global warming must start from the fact that, without the greenhouse effect, average temperatures would be perhaps 20 degrees Celsius lower, and the development of human civilisation as we know it would have been impossible. DAI is a marginal change, an 'enhanced greenhouse effect'.

8 n 2 bove.

9 A.C. Pigou, The Economics of Welfare (New Brunswick: Transaction Books, 1952 ed, 2002), 184. This passage is essentially taken from A.C. Pigou, Wealth and Welfare (London: Macmillan, 1912), 159. The common terminology of welfare economics which we shall use here, including the externality, is largely not to be found in The Economics of Welfare, but is of more recent coinage.

${ }^{10}$ K.W. Kapp, The Social Costs of Private Enterprise (Cambridge: Harvard University Press, 1950). After realising that the communist economies were certainly no better, Kapp reworked this book as The Social Costs of Business Enterprise (Cambridge: Harvard University Press, 1963). Kapp's difficulties in this respect obviously also beset the IPCC, which applies the externality argument to all the world's economies, including those that have little or no independent private sector, of which the PRC arguably still remains the most important example. But the point cannot be taken up here as the welfare economics of climate change policy simply are not sophisticated enough to sustain the discussion.
} 
the UK Treasury, 'the greatest example of market failure we have ever seen'.11 Industrialisation has been based on the emission particularly of carbon dioxide $\left(\mathrm{CO}_{2}\right)$, and so, from the environmental welfare economics perspective, the essential character of the modern world created by capitalism is based on the production of an externality. ${ }^{12}$ In the more high-flown contributions to the debate, the mitigation of global warming is seen as an important part of a fundamental 'civilisation' of markets. ${ }^{13}$ Against this background, carbon trading is the first truly global result of the development of a capacity to engage in international welfare economic intervention which has been strongly promoted by the UN since it sponsored an influential collection of papers on 'global public goods' in 1999.14

The argument for treating anthropogenic GHG emissions as a negative externality, as it is made out in the SR's representative thinking, ${ }^{15}$ is now so much a part of the normal worldview, not only of policy-makers but of the informed public, such as those with environmental concerns, as to need only the briefest rehearsal here. When making an investment decision according to the criterion of profitability, private investors analytically seek returns in excess of the costs of their investment. They will take such costs as have a price and so feature within their private accounting horizon into account when making their decision. But certain costs will not have a price because the investor has no contractual

${ }^{11}$ N. Stern, The Economics of Climate Change (Cambridge: Cambridge University Press, 2007), 1. Sir Nicholas has presented a somewhat revised version of his views in a more readily accessible form in N. Stern, $A$ Blueprint for a Safer Planet (London: Bodley Head, 2009). This statement largely incorporates Sir Nicholas' later belief that the SR significantly underestimated the costs of failure to reduce GHG emissions.

${ }^{12}$ In the global warming economic literature, this issue has largely been discussed in terms of assessing the claimed correlation between growth and a reduction of polluting activity per unit of growth known as the environmental Kuznets curve. G. Grossman and A. Kreuger, 'Economic Growth and the Environment' (1995) 110 Quarterly Journal of Economics 353.

${ }_{13}$ M. Callon, 'Civilizing Markets: Carbon Trading Between in vitro and in vivo Experiments' (2009) 34 Accounting, Organisations and Society 535. For Mr Porritt's contribution to this strophe, see J. Porritt, Capitalism as if the World Matters (London: Earthscan, 2005).

${ }^{14}$ I. Kaul, et al (eds), Global Public Goods: International Cooperation in the 21st Century (New York: Oxford University Press, 1999). The editors were officers of UNDP. On the UNDP web page promoting the book, the then UN Secretary General says the following: 'It is not beyond the power of political volition to tip the scales towards a more secure peace, greater economic well-being, social justice and environmental sustainability. But no country can achieve these global public goods on its own, and neither can the global marketplace. Thus our efforts must now focus on global public goods', at http://www.undp.org/globalpublicgoods. That the authors of this book were anxious to be seen to move away from command and control to a position claimed to be based on Coase is emphasised by a link on this webpage to Coase's famous critique of a core argument for the provision of public goods in his essay on 'The Lighthouse in Economics': R.H. Coase, The Firm, the Market and the Law (Chicago: University of Chicago Press, 1986), 187

${ }^{15} \mathrm{SR}$, sec 2.2. The SR has come under very substantial criticism, not only from those who challenge its reliance on the IPCC physical science basis and its economic case for climate change mitigation, eg N. Lawson, An Appeal to Reason (London: Duckworth Overlook, 2008), but from those who essentially share its basic position, which they believe it argues badly; eg an extremely strongly worded 2006 review of the SR by Professor Richard Tol, a leading member of IPCC Working Parties responsible for influential climate change modelling, led to a heated exchange culminating in G. Yohe and R. Tol, 'The Stern Review and the Economics of Climate Change: An Editorial Essay' (2008) 89 Climatic Change 231. But that the SR is the single most important welfare economic argument for the KP is indisputable, and we concentrate on it for that reason. 
relationship in respect of those costs with those who bear them. These social costs are real, but external to the market, and so play no part in a private investment decision, which may well, then, be wrong from a social perspective which takes all private and social costs into account. For Pigou, factory smoke was a clear example of an externality because those harmed by it had no contractual relationship with the factory owner in respect of that harm, which therefore was uncompensated. The SR represents a very influential body of opinion which believes anthropogenic GHG emissions to be a similarly clear example at a global scope and scale. The KP attempted to cap the developed countries' anthropogenic GHG emissions at certain 'assigned amounts' (AAs). Tradable credits are issued for reductions under the cap, which those wishing to emit in excess of the cap must purchase in order to do so, the possibility of sale and the necessity of purchase giving the emissions caught in this way a 'shadow' price (their market price being zero) which brings them within the accounting horizon of emitters and leads to carbon trading.

Though the externality argument is Pigouvian, this 'cap and trade' argument for carbon trading is not. The typical Pigouvian forms of intervention - public ownership or very direct regulation, taxation, and payments of bounties - are closely associated with command and control. But almost every work of theoretical substance, ${ }^{16}$ or pretension on carbon trading, makes reference to Coase's 'The Problem of Social Cost', which is identified as the fons et origo of market-mimicking as a fundamental improvement upon command and control as the basic form of regulatory technique. The SR identifies four possible 'ways in which negative externalities can be approached', the first three of which are of direct relevance to the analysis of the KP mechanisms. (The fourth, in essence global public ownership, is set aside as 'clearly not a practical option'). ${ }^{17}$ The first approach is taxation of the action causing the externality, the second is 'quantity restrictions' which 'limit the volume of emissions [...] using a command and control approach', and the third is the allocation of 'a full set of property rights [...] among those causing the externality and / or those affected [...] which can underpin bargaining or trading'. This third approach is based on the authority of a reference to 'Coase (1960)', ie to 'The Problem of Social Cost'. Cap and trade systems are analysed as a combination of the second and third approaches:

They control the overall quantity of emissions, by establishing binding emissions commitments. Within this quantity ceiling, entities covered by the scheme - such as firms, countries or individuals - are then free to choose how best - and where - to deliver emissions reductions within the scheme. ${ }^{18}$

\footnotetext{
${ }^{16}$ From within the legal scholarship, we would like to point to the excellent work of David Driesen as a counterpoint to our own position: eg 'Sustainable Development and Market Liberalism's Shotgun Wedding: Emissions Trading Under the Kyoto Protocol' (2008) 83 Indiana Law Journal 21.

$17 \mathrm{SR}, 353 \mathrm{n} 4$.

18 ibid, 353.
} 
This confidence in cap and trade is a product of the 'reconceiving' of the technique of the 're-regulatory state' during the 'age of regulatory reform' we have experienced over the past 40 years. Rather than attempt to intervene using the direct mechanisms advocated by Pigou, the national state and international agencies, having identified stabilisation of global warming as a public good but despairing of an adequate regulatory response based on traditional command and control, notably the impossibility of imposing biting carbon taxes, ${ }^{19}$ seek to produce that public good by constructing a 'quasi-market' which will lead to market-mimicking behaviour. Such use of quasi-markets has become the basic regulatory technique of the 'new public management' adopted by national governments throughout the developed world. The KP climate change mitigation strategy is one of market-mimicking at a global scope and scale, and as such embodies the regulatory technique of the new global welfare economics. In the words of Ms Christiana Figueres, whose recent appointment as Executive Secretary of the UNFCCC Secretariat will be discussed below, and Mr Ken Newcombe, another highly influential participant in the creation of carbon trading markets: ' $t$ the Protocol market mechanisms are [...] the first ever attempt of the United Nations to create and regulate a global commodity, a responsibility otherwise squarely in the hands of the private sector'. ${ }^{20}$

We wish to avoid discussion of the plausibility of the 'physical science basis' of global warming, which we will accept so far as possible. ${ }^{21}$ Through its exhaustive, continuously revised compilations of this science, ${ }^{22}$ which involve the international engagement of thousands of scientists and extensive global promotional and lobbying activities, a UN agency, the Intergovernmental Panel on Climate Change (IPCC), has managed to establish a 'scientific consensus' that 'dangerous anthropogenic interference' (DAI) with the global climate is taking place. Amongst a range of predictions, it is claimed that, if anthropogenic GHG

\footnotetext{
19 n 133 below.

${ }^{20}$ C. Figueres and K. Newcombe, Evolution of the CDM: Toward 2012 and Beyond (London: Climate Change Capital Ltd, 2007), 1, at http://www.climatechangecapital.com/media/articles-and-papers/evolution-ofthe-cdm.aspx.

21 Objectivity in this incredibly vexed area requires us, however, to state our position, that, whilst we are, to varying degrees, persuaded that global warming is taking place, we think it is most unwise to place the amount of confidence in the claims made in the physical science basis about its extent or its nature that is being placed on it in the economic policy debate, because the issues are far too difficult to admit of their description with anything remotely like the necessary certainty or precision. We all find the very idea of 'consensus science' to be simultaneously a rather silly and a repugnantly authoritarian representation of the actual practice of scientific research. For a recent review of the evidence which, though it gravely underestimates mensuration error in our view, strives to be objective, see Royal Society, Climate Change: $A$ Summary of the Science (September 2010), at http:/ / royalsociety.org/climate-change-summary-of-science.

22 IPCC, Climate Change 2007: The Physical Science Basis (Cambridge: Cambridge University Press, 2007). Since 1990, the IPCC has produced four Assessment Reports addressing all the physical and human aspects of climate change. The Fourth Assessment Report will be replaced by a fifth to be published in 2013. Since 2007, there have been, and will be, many ratchetings up of the 'reasons for concern' that will feed into the Fifth Assessment physical science report: eg J.B. Smith, et al, 'Assessing Dangerous Climate Change through an Update of the IPCC "Reasons for Concern"” (17 March 2009) 106(11) Proceedings of the National Academy of Science of the USA 4133.
} 
emissions continue to rise on current trends, global mean surface temperatures will rise by more than four degrees Celsius over pre-industrial levels by the end of this century, and the dangerous environmental effects of this are variously described by the IPCC in a number of 'emissions scenarios'. ${ }^{23}$ The response to this is to seek to limit anthropogenic GHG emissions, and therefore atmospheric GHG concentration, at a level which will curb the warming effect.

The UNFCCC's own emissions target is set out in art 2 in the most general, indeed tautological, terms of stabilisation at levels which prevent DAI. The KP gave some effect to the 'common but differentiated responsibilities' necessary for 'an effective and appropriate international response' to climate change which are established in the preamble to the UNFCCC, but in a way which takes only a very limited step towards setting concrete targets. As all countries emit GHGs to some extent, the responsibility for anthropogenic GHG emissions is common, but the UNFCCC clearly placed real responsibility, both in the sense of historical blame for global warming and in the sense of now doing most about it, on the developed countries, ${ }^{24}$ which were listed in Annex I. Under KP, art 3, para 1, essentially the same parties, identified in KP Annex B, accepted caps on their AAs which should have led to an at least five per cent average reduction of their anthropogenic GHG emissions from, for most countries, 1990 base levels by the end of a First Commitment Period (FCP) which will end in 2012.

This five per cent target is, in a strong sense, a random figure, for it is not related to necessary reductions in global anthropogenic GHG emissions in any rational way. ${ }^{25}$ No link between this target and the prevention of DAI has been or, as we shall see, could be drawn. The global target, for which the EU has since strongly argued in light of revised IPCC calculations about the danger posed by various concentrations of $\mathrm{GHG}, 26$ is a reduction of global emissions such that warming will be limited to a two degrees Celsius increase over pre-industrial temperatures, ${ }^{27}$ and the CA, para 1 , has adopted this target. As we have said, we wish so far as possible to avoid discussion of the physical science basis of global warming, but we must note here that identifying the concentration of GHG that will prevent DAI identified with the two degrees Celsius target is very widely agreed to be exceptionally difficult. There may be a consensus over global warming, but, on this vital point, policymaking is, in our opinion, undermined

\footnotetext{
${ }^{23}$ IPCC, Special Report on Emissions Scenarios (Cambridge: Cambridge University Press, 2001). This Report is based on data collected for the Third Assessment Report.

${ }^{24}$ UNFCCC, art 3, para 1. The Annex I parties included the then European Economic Community in its own right, and, though understandable, this may well have made European GHG emissions policy more difficult because it created a 'bubble' of emissions, regulatory responsibility for which was shared, or contested, between the 15 countries and the then European Community which were signatories to the KP.

${ }^{25}$ W. Nordhaus and J. Boyer, 'Requiem for Kyoto: An Economic Analysis' (1999) 20 Energy Journal Special Issue 93, 125.

${ }^{26}$ IPCC, Climate Change 2007: Mitigation of Climate Change (Cambridge: Cambridge University Press, 2007), box 13.7 .

${ }^{27}$ EU Climate Change Expert Group, The $2{ }^{\circ} \mathrm{C}$ Target, at

http://ec.europa.eu/environment/climat/pdf/brochure_2c.pdf.
} 
because it just cannot be said what the consensus is about. ${ }^{28}$ The target reduction has been set at numerous different levels and is under constant revision (particularly in response to the uncertainty left by COP15). The European Commission has determined that the EU should reduce its anthropogenic GHG emissions by at least 20 per cent from 1990 levels by 2020, and by between 80 per cent and 95 per cent by 2050, in order to achieve the two degrees Celsius target, ${ }^{29}$ and the UK has given statutory expression to reductions in line with this extremely ambitious target in the Climate Change Act 2008, s 1.

On the current industrial technology particularly of energy production, ${ }^{30}$ even the KP Annex 1 reductions of five per cent would impose immense costs, ${ }^{31}$ and, concerned, inter alia, about these costs, the USA, then the world's largest emitter and by far the single largest Annex I emitter, undermined the KP from the start by refusing to ratify it. This really was in itself enough to make the Annex I FCP target unachievable, but, fundamentally because of a similar unwillingness to bear these costs, the other Annex I countries had overall pursued the KP targets they had accepted in, to put it politely, half-hearted ways which have failed to set biting caps, ${ }^{32}$ and as a whole these countries were not on course to achieve their FCP

${ }^{28}$ M.R. Allen, et al, 'Warming Caused by Cumulative Carbon Emissions towards the Trillionth Tonne' (30 April 2009) 458(7242) Nature 1163: '[g]lobal efforts to mitigate climate change are guided by projections of future temperatures. But the eventual equilibrium global mean temperature associated with a given stabilization level of atmospheric greenhouse gas concentrations remains uncertain, complicating the setting of stabilization targets to avoid potentially dangerous levels of global warming'.

${ }^{29}$ EC, International Climate Policy Post-Copenhagen: Acting Now to Reinvigorate Global Action on Climate Change (COM(2010) 86 final, 9 March 2010), at

http://ec.europa.eu/environment/climat/pdf/com_2010_86.pdf A recent attempt to move to the 30 per cent reduction allowed for under the EU's commitment to the CA led by the new UK Climate Change Minister has been rejected at EU level. M. McCarthy, 'Huhne Presses EU on Raising Emissions Targets' The Independent (12 June 2010), at

http://license.icopyright.net/user/viewFreeUse.act?fuid=ODczNzMxMg$\% 3 \mathrm{D} \% 3 \mathrm{D}$.

30 The IPCC's treatment of the macroeconomic significance of the technological frontier is largely based on its depiction as one of four macro-economic 'drivers' (and therefore possible policy 'levers') determining GHG emissions levels in a formula called the 'Kaya identity' after its developer, Professor Yoichi Kaya. IPCC, n 23 above, ch 2. On possible (or otherwise) significant changes to the technological frontier, see M.I. Hoffert, et al, 'Advanced Technology Paths to Global Climate Stability: Energy for a Greenhouse Planet' (2002) 298(5595) Science 981.

31 UNDESA has recently reviewed the various estimates of these costs, which range from zero point two per cent to two per cent of the entire world's GDP per annum. UNDESA, World Economic and Social Survey 2009: Promoting Development, Saving the Planet (New York: UN, 2009), 154-155. Every such estimate we have examined seems unacceptably speculative and low. We are in an area where policy formulation is possible only by means of what may be the most marked example ever of the 'extravagant and exaggerated use' of inevitably defective economic data against which Morgenstern warned us in his seminal work on the accuracy of such data. O. Morgenstern, On the Accuracy of Economic Observations (Princeton: Princeton University Press, 2nd ed, 1963), 303.

32 Phase I of EUETS was marked by a collapse almost to zero of the price of permits issued under it, the result of the issuance of far more permits by governments scared of affecting growth to emitters than the emitters needed for business as usual, which, of course, eliminates the cap and thereby the scarcity of the permissions. Influential opinion about this undeniable farce has been that this was a valuable lesson of Phase I of EUETS from which future policymaking should learn. But it proved politically impossible in Phase II to avoid the 'grandfathering' of permits which had led to their excessive allocation in Phase I, and, prior to the current depression (n 34 below), it seemed extremely highly likely that Phase II, which is to end conterminously with the FCP, will have the same result as Phase I. Environmental Audit 
reductions prior to the current depression. ${ }^{33}$ Significant reductions between 1990 to 2007 can solidly (but by no means uncontroversially) be identified in the postcommunist countries, but these are attributable to the declines in the levels of overall economic activity these countries suffered during their difficult transitions, and the resumption of growth had put them on a course to more than nullify these reductions. Emissions in the advanced capitalist Annex I countries increased by at least 11 per cent between 1990 and 2007. The position left by the current depression cannot reliably be assessed as this is written, ${ }^{34}$ but we can ignore this for the problem is dealing with Annex 1 emissions given the growth targets to which Annex 1 countries typically aspire, and are now doing all they can to restore. For reasons which will emerge, it is even more important to note that certain developing countries have greatly increased their emissions, and in particular that the People's Republic of China (PRC) increased its emissions by 160 per cent over this period. In sum, from 1990-2007, global anthropogenic GHG emissions actually rose by over 40 per cent. Stated at its briefest, this extreme 'compliance gap' means that, prior to the depression, the Annex 1 countries were not on course to meet their FCP target, and the global situation was on course to have very substantially worsened.

The KP established three market-mimicking emissions trading schemes known as the 'flexible mechanisms'.35 The 'Emissions Trading' mechanism established under KP, art 17, and the 'Joint Implementation' mechanism established under art 6 envisage project development and trade within Annex I countries. The Clean Development Mechanism (CDM) established under KP, art 12 , is the flexibility mechanism which embraces the developing countries, including the PRC, India, and Brasil. Under the CDM, a 'project developer' proposes a 'carbon project' in a 'host' developing country which it is intended will

Committee, Fourth Report: The Role of Carbon Markets in Preventing Dangerous Climate Change (2009-2010) (HC 290). The failure of Phase I was described and an, it seems, accurate prediction of the failure of Phase II was made in Open Europe, Europe's Dirty Secret: Why the EU Emissions Trading Scheme Isn't Working (London: Open Europe, 2007), at http://www.openeurope.org.uk/research/etsp2.pdf. Though ending on what seems a ritualistic positive note, the appraisal of the EU climate change policy by Dieter Helm, Professor of Energy Policy at Oxford and a senior government advisor committed to climate change mitigation, seems to us very fair. D. Helm, 'EU Climate-Change Policy: A Critique' in D. Helm and C. Hepburn (eds), The Economics and Politics of Climate Change (Oxford: Oxford University Press, 2009), 222. In light of this, that there are great values traded on the EUETS (n 40 below) is enormously worrying, for it leads one to suspect there are no welfare-enhancing fundamentals underlying this trade. This is the kernel of sense in activist criticisms of a looming 'carbon subprime'. S-J. Clifton, A Dangerous Obsession (London: Friends of the Earth, 2009), sec 3.4.

33 UNFCCC Subsidiary Body for Implementation, National Greenhouse Gas Inventory Data for the Period 19902007 (FCCC/SBI/2009/12, 21 October 2009), at

http://unfccc.int/resource/docs/2009/sbi/eng/12.pdf. GHG emissions data are extremely difficult to interpret, not only because of allowances which must be made for the enormous problems of collecting even the basic 'physical' data, but even more because of the labyrinthine and politically contested way those data are aggregated to produce baselines, targets, and reductions which have important policy implications.

34 The latest UK position assessed by the CCC ascribes almost all of recent UK emissions reductions to the depression. CCC, Meeting Carbon Budgets: Ensuring a Low Carbon Recovery (2nd Progress Report, 30 June 2010), at http://www.theccc.org.uk/reports/progress-reports.

35 See generally D. Freestone and C. Streck (eds), Legal Aspects of Carbon Trading (Oxford: Oxford University Press, 2009). 
secure reductions in the projected anthropogenic GHG emissions of that country. After establishing a baseline of the emissions which would be caused by a proposed investment, ${ }^{36}$ a developer may seek approval of alterations to the investment which would reduce the emissions it would have caused. A UN agency, the CDM Executive Board (CDMEB), lays down mandatory methodologies for the design of various types of carbon project, ${ }^{37}$ oversees the approvals process, grants final approval to, and oversees the monitoring of carbon projects. Tradable 'Certified Emissions Reductions' (CERs), denominated in metric tonnes of $\mathrm{CO}_{2}$ equivalent $\left(\mathrm{CO}_{2} \mathrm{e}\right),{ }^{38}$ are issued for validated reductions.

CERs may be used by 'credit buyer' public and private emitters in Annex I countries as 'carbon credits' to 'offset' their own reductions required by a domestic cap. The finance for the technological transfer and innovation that would so modify the investment as to reduce its emissions is to be obtained from sale of the CERs. In this way, it was intended that very substantial foreign investment in and transfer of 'low carbon technology' would take place, encouraging 'sustainable development' in non-Annex 1 countries. As this would be undertaken principally by private parties seeking to offset emissions in Annex I countries (or sell permissions to do this), 'market forces' would identify the most efficient ways of obtaining emissions reductions in non-Annex I countries in a beneficent process of 'environmental entrepreneurship'. It was also intended that the secondary market which would emerge in CERs ultimately would be combined with other emissions markets around the world to establish a global carbon market on which a single price for carbon would eventually emerge. ${ }^{39}$ As the USA almost certainly will not play a part under the KP within the FCP, overwhelmingly the most significant market, ${ }^{40}$ for trade in CERs in Annex I countries, is the European Union Greenhouse Gas Emissions Trading Scheme (EUETS), ${ }^{41}$ under a Directive which links to the CDM to the EUETS. ${ }^{42}$

It must be stressed that the KP imposed no caps on the non-Annex I 'developing' countries, which were not required to make reductions within the

\footnotetext{
36 The basic methodologies contemplate a large scale industrial investment. Variations of these methodologies are made for other types of project. The requirements of the CDM approvals process have been relaxed for small-scale projects, which are thought not to be able to bear their cost, and this is very troubling indeed in light of the history of the operation of the CDM discussed below. We fear this will prove to be more or less a license for opportunistic action which will be tolerated so long as it is kept within small bounds.

${ }^{37}$ It is open to the developer of a project so innovative that it requires a novel methodology to propose such a methodology to the CDMEB.

${ }^{38}$ The significance of this unit is described in the text accompanying $\mathrm{n} 92$ below.

${ }^{39} \mathrm{SR}, \mathrm{ch} 22$.

40 In 2008, the value traded on the EUETS was USD 92 billions, ie over 73 per cent of the total value of the transactions conducted on world carbon markets. K. Kapoor and P. Ambrosi, State and Trends of the World Carbon Market 2009 (Washington DC: World Bank, 2009), table 1.

${ }^{41}$ Directive 2003/87/EC, as amended by Directive 2009/29/EC. As we have mentioned, the end of Phase II of the EUETS will coincide with the end of the KP SCP. For the EU's intentions for Phase III after this, see EC, 2020 by 2020: Europe's Climate Change Opportunity (COM(2008) 30 final, 23 January 2008), at http://www.energy.eu/directives/com2008_0030en01.pdf.

42 Directive 2004/101/EC.
} 
FCP, and that nothing that has happened since has changed this. The UNFCCC seemed to contemplate an absolute growth in these countries' emissions, ${ }^{43}$ to allow of their 'economic development', ${ }^{4}$ which is given explicit priority over reduction of anthropogenic GHG emissions, ${ }^{45}$ and the KP itself is silent about how those countries would ever contribute to the common responsibility in any substantial sense. Now, incredible as it first seems to say, the consequence of this is that the CDM cannot lead to any GHG reductions at all. A CER, denominated as one tonne of $\mathrm{CO}_{2} \mathrm{e}$, is generated by a reduction in a non-Annex1 host. The CER will be used by an emitter in an Annex I country to emit a tonne of $\mathrm{CO}_{2} \mathrm{e}$. It is this possibility that makes the purchase of the CER, and thus the financing of carbon projects, rational for parties in Annex I countries. The global position over emissions therefore will not be changed by a clearing CDM market, ie a market in which CERs are not hoarded. The KP imposes no limit to the activity which can go on in this way. The remarkable point which must be made is that, although discussion of the KP flexible mechanisms is typically conducted as a discussion of cap and trade markets, as it is throughout the SR, ${ }^{46}$ the CDM, unlike the other KP mechanisms, is not capped, and this means that the KP mechanisms as a whole are not capped.

Even if the CDM worked, it could reduce only the 'carbon intensity' of economic activity in non-Annex 1 countries. This is the measure of the amount of anthropogenic GHG which must be emitted to increase gross domestic product (GDP), ${ }^{47}$ which indeed would be reduced by sustainable development financed under the CDM. But reduction in carbon intensity may be perfectly consistent with unbounded absolute growth in anthropogenic GHG emissions, and, in countries which are actually developing such as the PRC, it is, in a practical sense, inevitable that reduction in the former will be accompanied by growth in the latter. As old, more carbon intensive plant can be retired only gradually, extremely ambitious reductions in carbon intensity actually require a very substantial installation of new, less carbon intensive plant in order to lower the average carbon intensity of the whole economy by increasing overall GHG emissions.

In these circumstances, the idea of there actually being a common but differentiated responsibility is completely undermined. The UNFCCC and the KP do not place a different responsibility on the non-Annex 1 countries. They place no responsibility whatsoever on them, and therefore there is no common responsibility as steps taken in recognition of any responsibility borne by the Annex 1 countries may well be entirely fruitless, for reductions in those countries may well be negated by increases in non-Annex 1 countries, as we will see has

\footnotetext{
43 UNFCCC, preamble.

44 ibid, art 3 , para 4.

45 ibid, art 4, para 7, reads: 'The extent to which developing country Parties will effectively implement their commitments under the Convention [...] will take fully into account that economic and social development and poverty eradication are the first and overriding priorities of the developing country Parties.'

$46 \mathrm{nb}$ SR, 353.

47 The literature contains other definitions of carbon intensity.
} 
been the case. Overall emissions reductions can happen only if the non-Annex I countries also are subject to caps, for then trade between a host and a buyer becomes trade between two capped systems, and reductions will follow, in respect of the emissions caught and to the extent that market-mimicking works, in the optimal way. The extent to which it was initially envisaged that the common responsibility would eventually 'evolve' to impose substantial burdens on the nonAnnex I countries is a matter of contentious diplomatic history. ${ }^{48}$ Though the UNFCCC and the KP make no sense unless it was believed that the non-Annex I countries would eventually commit to reductions, and that the KP would make such commitment easier because those countries had been drawn in to carbon trading which would greatly reduce the cost of those reductions, there is nothing in either the Treaty or the Protocol to lead one to think this will happen; quite the contrary is in fact the case.

This began to become undeniably clear when the 31 January 2010 deadline for notifications of reductions commitments to the CA passed without any meaningful result, ${ }^{49}$ other than the then Executive Secretary of the UNFCCC Secretariat trying to put the bravest face on things, including by denying that 31 January had ever been a deadline in the usual sense of the word at all, ${ }^{50}$ prior to himself resigning, having become identified with the failure of COP15.51 Of course, our description of these notifications as having no substantial content would by no means be conceded by those promoting the KP. Mr Ed Miliband, now the Leader of the UK Labour Party, in his former role as Secretary for the Environment and Climate Change under the previous Government, claimed that '[j] ust one month after Copenhagen, countries accounting for nearly 80 per cent of global emissions have shown they're pushing ahead with domestic action on climate change [with] the USA, China and India setting out what they will do'.52

But, even if one puts aside the great difficulties of saying what any target means in this vexed area, none of these countries has made any sort of substantial commitment to reduce emissions. The USA's statement is of a 'target' for reductions from a 2005, not 1990, baseline, and, not only is the start of pursuit of this target made explicitly conditional on other Annex I parties and the 'more advanced' non-Annex I parties making substantial commitments of just the sort they did not make at COP15, but the target itself is expressed in, in the words of its notification, 'pending legislation' that has little prospect of surviving Congress.

\footnotetext{
48 S. Oberthur and H. Ott, The Kyoto Protocol (Berlin: Springer Verlag, 1999), sec 17.1.

49 The notifications received by the UNFCCC Secretariat are available at http://unfccc.int/home/items/5262.php.

${ }^{50}$ J. Vidal, 'UN Drops Deadline for Countries to State Climate Change Targets' The Guardian (20 January 2010), at

http://www.guardian.co.uk/environment/2010/jan/20/copenhagen-accord-deadline-climate-change.

51 J. Vidal, 'Yvo De Boer's Successor has Big Footprints to Fill' The Guardian (18 February 2010), at

http://www.guardian.co.uk/environment/2010/feb/18/yvo-de-boer-successor-analysis.

52 DECC, Ed Miliband Responds to Copenhagen Accord Deadline (Press Release, 2 February 2010), at http://www.decc.gov.uk/en/content/cms/news/pn2010_14/pn2010_14.aspx.
} 
The USA's notification is entirely representative of the weakness of Annex I notifications. ${ }^{53}$

Leaving aside incidentals, the PRC's notification is as follows:

China will endeavour to lower its carbon dioxide emissions per unit of GDP by $40-45$ per cent by 2020 compared to the 2005 level [...] Please note that the above-mentioned autonomous domestic mitigation actions are voluntary in nature and will be implemented in accordance with the principles and provisions of the UNFCCC, in particular Article 4, paragraph 7.

To spell it out: this is a notification of a 'voluntary' 'endeavour' related to 2005, not a 1990, baseline, which is explicitly stated to be of no legal status. The notification is expressed in terms of carbon intensity and is entirely within the framework of the UNFCCC art 4, para 7, though we have seen that reduction in carbon intensity is perfectly reconcilable with, and almost certainly will mean, great growth in absolute anthropogenic GHG emissions, and that art 4, para 7, explicitly privileges economic growth over emissions reduction. India's notification is more or less the same except that it enters even more reservations. The notifications of all other non-Annex I countries are in this vein.

In sum, the best that can be said of Mr Miliband's interpretation of the CA is that it is based on a persistent belief that COP16, due to start in Cancun, Mexico, in November 2010, will achieve what COP15, and the entire history of UNFCCC diplomacy, has not. ${ }^{54}$ But such a commitment reminds us of Einstein's definition of insanity as doing the same thing over and over again in the expectation of different results, only in this case the repetition is extremely costly, and, in our opinion, the failure of COP15 marks the point where it no longer sensible to assert that the KP process has secured commitments to the caps needed to make the CDM work even in theory, though one would be foolish to think that the

\footnotetext{
${ }^{53}$ Since this was written, J. Rogelj, et al, 'Copenhagen Accord Pledges Are Paltry' (2010) 464(7292) Nature 1126, has passed a very critical verdict on the Annex 1 countries' commitments to the CA, but it is not nearly critical enough, in our opinion, for it reads far too much into these pledges. It does, however, usefully criticise a number of commentaries on the CA, including by Sir Nicholas Stern, that put a gloss on CA notifications similar to Mr Miliband's.

${ }^{54}$ N. Chestney, 'Britain Confident of Climate Deal in Mexico' Reuters (13 January 2010), at

http://uk.reuters.com/article/idUKTRE60C6JX20100113. It was inevitable that the UNFCCC has claimed that 'important progress towards concluding what was left incomplete at [COP15]' was made at the Bonn Climate Change talks held in June 2010, preparing the way for Cancun. UNFCCC, 'Bonn Climate Change Talks Make Progress on Fleshing Out Specifics of Global Climate Change Regime' (Press Release, 11 June 2010), at

http://unfccc.int/files/press/news_room/press_releases_and_advisories/application/pdf/20101106_pr _closing_june.pdf. In our opinion, based on the so far limited official documentation and media accounts, no substantial progress whatsoever was made at these talks. Whilst this paper was being reviewed for publication, negotiations held in Tianjin, PRC as a preliminary to COP16 ended in further recrimination and it became clear that attempts would be made to revise down the COP16 agenda to minimise the embarrassment caused by the failure of the KP. L. Gray, 'Global Warming Summit Heads for Failure Amid Snub By World Leaders' The Daily Telegraph (11 October 2010), at http://www.telegraph.co.uk/earth/copenhagen-climate-change-confe/8053853/Global-warmingsummit-heads-for-failure-amid-snub-by-world-leaders.html.
} 
immense commitments which have already been made to carbon trading will be unwound with alacrity. The UNFCCC has met with great success in generating support for carbon trading from very powerful public and private interests, ${ }^{55}$ and the point at which the complete and irremediable failure of the KP is, as it were, officially acknowledged no doubt will be delayed long after the evidence of that failure is compelling. Nevertheless, without a cap on the non-Annex I countries, those countries present a theoretically unbounded extensive margin for an increase of emissions, with the limits in Annex I countries merely being relaxed in nonAnnex I countries, a problem commonly referred to as 'carbon leakage' from one country to another. Indeed, in an inversion of the argument for technology transfer, as CERs are ultimately priced by the value of the emission of a tonne of $\mathrm{CO}_{2} \mathrm{e}$ in a rich Annex I country, it is readily conceivable that the revenues from this will stimulate emissions in a poor non-Annex I country in a way which would not be possible were the underlying project to be funded from within that country, and we will see that highly persuasive evidence of this emerges from the operation of the CDM in the PRC.

Despite all this, the CDM has been claimed to be a great success, ${ }^{56}$ which, in a diplomatic sense it indisputably has been. Since the first project registration on 18 November 2004, ${ }^{57}$ the CDM has registered 2029 projects ${ }^{58}$ in 63 host countries, ${ }^{59}$ with approximately 2500 projects in an approvals pipeline which has grown beyond all initial expectation. ${ }^{60}$ In 2008, the value of the CERs issued was estimated to be more than USD six point five billions, the transacted value on the CDM secondary market was USD 26 billions, and the total transacted value on the world emissions markets then established was USD 126 billions. ${ }^{61}$ Prior to the conclusion of COP15, the CDM was predicted to issue two point nine billion CERs by the end of the FCP. ${ }^{62}$ Undeniably, a large and growing market in a new financial instrument has been created.

However, CER issuance and trade is still vestigial by comparison to the size of the problem to which it is addressed. Meeting any UNFCCC emissions target will require, in the words of the UN Secretary General, 'a wholesale reconfiguration of global industry', ${ }^{63}$ a 'global transformation' amounting to what

\footnotetext{
55 S. Boehmer-Christiansoen and A. Kellow, International Environmental Policy: Interests and the Failure of the Kyoto Process (Cheltenham: Edward Elgar, 2002).

56 eg R. Purdy, 'Governance Reform of the Clean Development Mechanism After Poznań' (2009) 1 Carbon and Climate Law Review 5.

57 Many early projects have a CER issuance backdated to 1 January 2000 in recognition of the delays between the agreement of the KP and making CDM regulations and procedures operational.

58 CDM website, at http://cdm.unfccc.int/Statistics/index.html. The UNEP Risø website maintains a more detailed pipeline analysis, at http://cdmpipeline.org/.

${ }^{59} \mathrm{CDM}$ website, at

http:/ /cdm.unfccc.int/Statistics/Registration/NumOfRegisteredProjByHostPartiesPieChart.html.

${ }^{60} \mathrm{CDM}$ website, $\mathrm{n} 58$ above.

61 Kapoor and Ambrosi, n 40 above, table 1.

62 CDM website, n 58 above.

63 UN Secretary General, 'A New Green Economics' (Press Rrelease, 3 December 2007), at
} 
is commonly referred to as 'a second industrial revolution'.64 And, indeed, a deliberate alteration of the basic nature of the entire energy economy, and therefore the entire economy, of the entire world is being attempted. On the basis of broadly the figures that led to the formulation of the two degrees Celsius target, in 2007 the SR envisaged global carbon market capital flows in the order of USD 40 billions per annum, and the UNFCCC Secretariat envisaged flows in the order of USD 100 billions. ${ }^{65}$ If one allows that the issuance of a CER represent a reduction of emissions by one tonne $\mathrm{CO}_{2} \mathrm{e}$ and sets this against the non-Annex 1 country emissions reductions necessary to meet the two degrees Celsius target on the assumption that Annex 1 countries will meet 80 per cent of the global burden, then, on our own calculations, if this is the right word for something so speculative, these figures seem to us to be marked underestimates produced at an early stage of the debate, and the subsequent literature is replete with predictions of the growth of the carbon market magnitudes greater than the SR's. Point Carbon, one of a number of international carbon market intelligence providers that have been set up and flourished since the UNFCCC, predicts that the value traded on global carbon markets will reach USD three point one trillions by 2020.66 The UN Department of Economic and Social Affairs calls the current financing of sustainable development in non-Annex 1 countries 'the global financial mismatch of the century', ${ }^{67}$ and believes that 'the scale of financing [required for] the energy transition is several orders of magnitude greater than that available through current financing arrangements'. ${ }^{68}$ However this is, so long as we have managed to convey the astronomical size of the task set for the CDM by the $\mathrm{KP},{ }^{69}$ the point is in a sense not worth arguing, for, we repeat, a CER does not represent a reduction of $\mathrm{CO}_{2} \mathrm{e}$ at all. Unless there are non-Annex 1 caps, the $\mathrm{CDM}$ cannot actually make any contribution to GHG reductions, and so any attempt to

http://www.un.org/sg/press_green_economics.shtml. UNDESA has produced an enormous amount of research which is the background to The Secretary General's views: nb UNDESA, n 31 above.

${ }^{64}$ eg J. Jenkins, 'Energy Secretary Steven Chu: Honorary Breakthrough Fellow?' Breakthrough Generation (9 February 2009), at http://breakthroughgen.org/2009/02/13/energy-secretary-steven-chu-honorarybreakthrough-fellow/. This article reports the views of Dr Steven Chu, the Secretary of Energy in President Obama's administration. Cognisant that a second industrial revolution has already been distinguished by certain economic historians, other variants call for a third industrial revolution.

${ }_{65} \mathrm{SR}, 521$.

${ }^{66}$ Point Carbon, 'Carbon Market Transactions in 2020: Dominated by Financials?' Carbon Market New Service (21 May 2008), at http://www.pointcarbon.com/1.917962 Many of Point Carbon's services, including this one, are accessible only upon subscription.

${ }^{67}$ UNDESA, 'Financing Mitigation and Adaptation by Developing Countries' (August 2009), UNDESA Policy Brief 22, 1.

${ }^{68}$ UNDESA, 'Climate Change and the Energy Challenge' (August 2009) UNDES A Policy Brief 24, 2.

${ }^{69} \mathrm{It}$ is also fair to say that this task will have to be accomplished with extraordinary speed. But we wish to avoid discussion of the timescale for making emissions reductions in line with the two degrees Celsius target or other targets that have played a part in the debate. So shifting and vexed, even by the standards of climate change policy, is this issue, in which the language of 'irreversible change', 'tipping points', and 'catastrophe' is widely used, that we have concluded that its proper treatment would require an article in itself. It is probably sensible to allow the 23 years between the conclusion of the KP in 1997 and 2020 as the period for assessing the KP, but every part of this claim could be contested. In a very instructive paper, Helm has perforce described as 'very grim' the prospects for success after looking the problem of the time set for achieving that success. D. Helm, 'Climate Change Policy: Why Has So Little Been Achieved?' in Helm and Hepburn, n 32 above, 9, 34. 
be at all specific about the size it would have to reach to materially contribute to the two degrees Celsius target is simply pointless.

\section{THE PROBLEM OF THE SUCCESS OF THE PRC}

The way that the common but differentiated responsibilities were conceived has turned out to be fundamentally mistaken. Without passing any comment on the responsibility of the Annex I countries in itself, the main problem is, as was pointed out when this paper was first presented, ${ }^{70}$ and as became abundantly clear at COP15, not the Annex 1 countries but certain of the non-Annex I countries which the CDM invites to become hosts. ${ }^{71}$ The UNFCCC was diplomatic in referring to the non-Annex 1 countries as 'developing', for most of them were not and unfortunately are not substantially developing, and so are tantamount to irrelevant to the problem of global warming as their emissions are so small. However, over the past 30 years, the formerly overwhelmingly dismal science of development economics has taken on a far more gay aspect as it has been able to record the addition of the PRC, ${ }^{72}$ India, and Brazil, which formerly had seemed mired in poverty, to the set of newly industrialising countries, creating a 'platinum age' of growth at rates even greater then the post-war 'golden age' enjoyed by the advanced capitalist economies. ${ }^{73}$ Previously based on the east Asian dragon economies, the newly industrialising countries had included no countries of substantial size, but these are the world's first, second, and fifth most populous countries, with populations of, respectively, 1.336 billions (almost 20 per cent of world total), 1.176 billions (almost 17 per cent) and 192 millions (almost three per cent). ${ }^{74}$ The growth of these countries poses, however, grave problems for GHG

\footnotetext{
70 M. Grubb, et al, The Kyoto Protocol (London: Earthscan, 1999), had placed early emphasis on the importance of the CDM.

71 R. Garnaut, et al, 'The Implications of Rapid Development for Emissions and Climate-change Mitigation' in Helm and Hepburn, n 32 above, 81. This argument is made with a concentration on the PRC specifically in R. Garnaut, et al, 'China's Rapid Emissions Growth and Global Climate Change Policy' in L. Song and W.T. Woo (eds), China's Dilemma: Economic Growth, the Environment and Climate Change (Washington DC: Brookings Institution, 2008), 170.

72 See T. Carlyle, 'Occasional Discourse on the Negro Question' (December 1849) 40(no 240) Fraser's Magazine for Town and Country 670, 672.

${ }^{73}$ In addition to their joint action with South Africa over climate change (n 3 above), these countries have, with Russia, been identified in some business literature as the 'BRIC' group of industrialising countries with large or very large populations. The development of any coordinated international position by the BRIC countries is at a very early stage. T. Halpin, 'Brasil, Russia, India and China Form Bloc to Challenge US Dominance' The Times (17 June 2009), at

http://www.timesonline.co.uk/tol/news/world/us_and_americas/article6514737.ece. We focus on Brazil, India, and the PRC, not because of any coordinated position on climate change which they have taken or will take, but because of the objective problem they commonly pose to the reduction of GHG emissions.

74 World Bank, World Development Report 2010: Development and Climate Change (Washington DC: World Bank, 2010), table 1.
} 
reduction. In the interests of brevity, we will confine ourselves to the PRC, but what we are about to say applies to India and Brazil as well. ${ }^{75}$

Since 1978, the PRC economy has grown by over 1,000 per cent, ${ }^{76}$ to the point where, with a GDP of almost USD4.5 trillions (six point five per cent of world total), it is now the third largest economy in the world, behind the USA and Japan, albeit a long way behind the USA, which has a GDP of over USD14 trillions (over 25 per cent of world total). ${ }^{77}$ However, the PRC remains overwhelmingly a poor country, with a per capita income of only 12 per cent of that of the US, and it is committed to continuing with this rate of growth in order to generalise the wealth now mainly enjoyed in coastal regions throughout its immense hinterland, in which around one half of a billion people still live on $\leq$ USD two per day. ${ }^{78}$ Although such forecasting is, of course, intrinsically extremely difficult, the PRC has been authoritatively forecast to overtake the USA as the world's largest economy by 2030 at the latest. ${ }^{79}$ As a necessary condition of this growth, the PRC's power generation capacity, which is based on utilisation of its immense reserves of coal, is predicted to expand enormously. In 2006, the PRC had 350 gigawatts of coal-fired power generation capacity. It plans to install an additional (net of retirements) 600 gigawatts (with ancillary transmission and distribution systems) by 2030.80 To put this into context, in 2008 , the entire coalfired power generation capacity of the US was 313 gigawatts (31 per cent of total US power generation capacity). ${ }^{81}$ This is to say, by 2030 China plans to install additional coal-fired power generation capacity equal to almost 200 per cent of existing US capacity.

The crucial part the CDM must play in the development of global carbon trading follows from these facts, which show that the economic success of the PRC poses the main challenge to global climate change mitigation. The PRC

\footnotetext{
75 The residuum of what were the 'developing countries' under the UNFCCC are now recognised as a distinct category of 'least developed countries' (using terminology generally employed by the UN) by the UNFCCC Secretariat, and these countries do seem to be forming a distinct negotiating bloc, distinct from the BRIC countries with which they are normally united in the Group of 77 plus China, certainly after COP15 showed the divergence of interest between the least developing countries and the actually developing countries with large populations. J. Kyalimpa, 'Climate Change: Least Developed countries Spell Out Demands' InterPress Service News Agency (11 December 2009), at

http://ipsnews.net/africa/nota.asp?idnews=49649. The situation of these countries is the principal concern in the debate about 'climate justice'. A.D. Sagar, 'Wealth, Responsibility, and Equity: Exploring an Allocation Framework for Global GHG Emissions' (2000) 45 Climatic Change 511. Certain UNFCCC policies are directed at the least developed countries, but they need not be discussed here.

76 A. Heston, et al, Penn World Table Version 6.3 (Centre for International Comparisons of Production, Income and Prices at the University of Pennsylvania, August 2009), at

http://pwt.econ.upenn.edu/php_site/pwt_index.php.

77 World Bank, n 74 above, table 4. Since this was drafted, it would seem that the PRC may have overtaken Japan as the world's second largest economy and certainly is on course to do so in the near future.

78 ibid, table 2.

79 A. Maddison, Chinese Economic Performance in the Long-Run (Paris: Development Centre of the OECD, 2nd ed, 2007), fig 4.1.

${ }^{80}$ Energy Information Administration, International Energy Outlook 2009 (US Department of Energy/EIA0484(2009), fig 46 and associated text, at http://www.eia.doe.gov/oiaf/ieo/pdf/0484(2009).pdf.

81 Energy Information Administration, Electric Power Annual 2008 (US Department of Energy/EIA0348(2008)), table ES1, at http://www.eia.doe.gov/cneaf/electricity/epa/epa.pdf.
} 
recently replaced the USA as the world's largest emitter of anthropogenic GHGs, now being responsible for over 20 per cent of global emissions. ${ }^{82}$ It has done this whilst its per capita emissions, which in 1990 were on a par with those of, say, subSaharan countries, are still less than a quarter of those of the US, but will, of course, further increase as a corollary of economic growth. ${ }^{83}$ The PRC currently is responsible for more than half of the global growth in emissions, and this trend vis a vis Annex 1 countries must markedly strengthen on current trends. ${ }^{84}$ The PRC presents then, for practical purposes, an unbounded extensive margin for anthropogenic GHG emissions.

In this situation, unless the PRC substantially contributes to emissions reduction, it does not matter what the rest of the world does, or, specifically, what the Annex I countries do, even if the US is included; much less what the UK, responsible for less than two per cent of global emissions, itself does. The global nature of the externality on which the KP strategy turns will then work against Annex I reductions, making them pointless, unless the PRC makes concomitant reductions. What has so far happened under the KP could not more forcefully bear this out. At the end of the FCP, the increase in PRC emissions will be in the order of 1,000 per cent of the total of the reductions the Annex I countries were to make under the KP. 85 This particular inconvenient truth did not sufficiently forcefully impress itself on UNFCCC negotiations until recently, but a growing perception that something radical had to be done about PRC emissions was the major issue that derailed COP15, leading to the PRC now being subjected to something like the criticism previously directed at the USA. ${ }^{86}$

In our opinion, to take this attitude towards the PRC fails to give proper weight to two considerations. ${ }^{87}$ First, it is highly arguable that the Communist Party has no practical political possibility of substantially revising down its growth targets, for political stability in the PRC now depends on meeting those targets. 88 It is also highly arguable that, even were it to have room to manoeuvre, the PRC would choose not to abandon those targets because it genuinely believes that the

82 International Energy Agency, Key World Energy Statistics (Paris: IEA, 2009), 49-57, at http://iea.org/textbase/nppdf/free/2009/key_stats_2009.pdf.

83 World Bank, n 74 above, table A1.

${ }^{84}$ J.S. Gregg, et al, 'China: Emissions Pattern of World Leader in $\mathrm{CO}_{2}$ Emissions from Fossil Fuel Consumption and Cement Production' (2008) 35(8) Geophysical Research Letters LO8806. The latest evidence seems, incredibly, to show a strengthening of these trends. M. Shealy and J.P. Doran, 'Growing Chinese Coal Use: Dramatic Resource and Environmental Implications' (2010) 38 Energy Policy 2116.

${ }^{85} \mathrm{M}$. Auffhammer and R.T. Carson, 'Forecasting the Path of China's $\mathrm{CO}_{2}$ Emissions Using Province Level Information' (2008) 55 Journal of Environmental Economics and Management 229.

86 S. Coates and J. Macartney, 'China to Blame for Failure of Copenhagen Climate Deal, Says Ed Miliband' The Times (21 December 2009), at

http://www.timesonline.co.uk/tol/news/environment/article6964106.ece. This article reports the views of the then Secretary for the Environment and Climate Change. See also n 54 above.

87 Or three, when it is acknowledged that the PRC's stance is perfectly legitimate in terms of what was agreed in the UNFCCC and all subsequent negotiations including the CA.

${ }^{88}$ D.L. Yang, Remaking the Chinese Leviathan: Market Transition and the Politics of Governance in China (Stanford: Stanford University Press, 2006). 
welfare cost of perpetuating the still very low living standards of the bulk of its population outweighs the welfare gains from anthropogenic GHG reduction. Its 2007 National Climate Change Programme, prepared at the behest of the UNFCCC Secretariat, argues this position, ${ }^{89}$ which was firmly stated in its notification to the CA. However this is, the PRC's stance at COP15, predicted in earlier versions of this paper, is no surprise for we believe that the combined weight of these two considerations will prevent the PRC ever committing to anthropogenic GHG emissions reductions that will allow the world to stay within the two degrees Celsius limit. More or less the same can be said for India and Brazil.

\section{THE OPERATION OF THE CDM IN THE PRC}

At the time of the agreement of the KP, the climate change threat was regarded as a major policy opportunity. The PRC was not going to be required to forego development but the CDM was to facilitate the transfer of and innovation in emissions reduction technology so that, in particular, the expansion of PRC power generating capacity would not undermine global emissions targets. In the absence of the USA, the EUETS has been by far the major Annex I institution for CDM trade generally, and the European Commission has established an EU-China CDM Facilitation Project which 'aims to strengthen the [CDM] as a central pillar within China's path to sustainable development'. ${ }^{90}$ European parties wishing to offset their emissions would be able, by the purchase of CERs, effectively to pay PRC power generators to invest heavily in emissions reduction, from which the PRC would both directly benefit in terms of reduced emissions and indirectly benefit by building upon the technology transfer to reduce the carbon intensity of growth more generally. As the EU-China CDM Facilitation Project puts it:

China and the EU['s] partnership on climate change [...] contains two concrete co-operation goals to be achieved by 2020. The first is to demonstrate and develop, in China and the EU, advanced near 'zero emissions' coal technology. The second goal is to significantly reduce the cost of key technologies and to promote their deployment and dissemination. Furthermore, the Partnership also aims to reinforce EU-China cooperation through the Kyoto Protocol's Clean Development Mechanism (CDM) by strengthening the implementation of CDM, facilitating the exchange of information on CDM projects and encouraging both European and Chinese companies to engage in $\mathrm{CDM}$ project co-operation.

\footnotetext{
89 National Development and Reform Commission of the PRC, China's National Programme for Climate Change (June 2007), at http://www.china.org.cn/english/environment/213624.htm. For a range of perspectives on this crucial issue see Song and Woo, n 71 above.

${ }_{90}$ EU-China CDM Facilitation Project website, at http://www.euchina-cdm.org/\#.
} 
Though the PRC dominates CDM activity, hosting almost 50 per cent of CERs issued, ${ }^{91}$ the attempt to realise these goals through the operation of the CDM has been so marked a failure as to amount to a farcical waste of resources. The initial growth of CDM activity very substantially turned on the opportunistic manipulation of the architecture of the KP. Though discussion of global warming commonly refers only to the effect of $\mathrm{CO}_{2}$, CERs are measured, ${ }^{92}$ not in $\mathrm{CO}_{2}$, but in $\mathrm{CO}_{2} \mathrm{e}$ because Annex B to the KP identified a 'basket' of six anthropogenic GHGs: in addition to $\mathrm{CO}_{2}$, methane, nitrous oxide, sulphur hexafluoride, the hydroflourocarbons (HFCs), and the perfluorocarbons. The last two are groups of gasses which are rare in nature and largely are industrial products. ${ }^{93}$ HFCs are widely used in the electronics industry and as flame retardants, propellants, and refrigerants, their use having significantly increased since the Montreal Protocol, for they are substitutes for ozone depleting gases identified under that Protocol. ${ }^{44}$ Up to 2007 , the great majority of the CERs, ${ }^{95}$ of a value estimated to reach almost USD five billions by the end of the FCP, ${ }^{96}$ were issued, not in relationship to power generation, or directly in relationship to $\mathrm{CO}_{2}$ at all, but in relationship to $\mathrm{HFC}_{23}$, a by-product of the production of $\mathrm{HFC}_{22}$, a valuable refrigerant gas. ${ }^{97}$

This prima facie curious concentration of CDM activity, not on the central activity of power generation, but on a miniscule part of the PRC economy, is readily explicable by reference to the way the $\mathrm{CDM}$ works. The IPCC views $\mathrm{CO}_{2}$ as the most significant anthropogenic GHG because of the vast volumes of it that are emitted, but it is by no means the most potent GHG. During the time when the $\mathrm{CDM}$ was being established, the IPCC gave $\mathrm{HFC}_{23}$ a Global Warming Potential (GWP) rating of 11,700 , which is to say $\mathrm{HFC}_{23}$ is stated to be 11,700 times more potent a global warming gas than $\mathrm{CO}_{2} .{ }^{98}$ This means that, for every tonne of $\mathrm{HFC}_{23}$ that is not emitted in a non-Annex I country, CERs allowing 11,700 tonnes of emission of $\mathrm{CO}_{2}$ in an Annex I country will be issued. As it

$91 \mathrm{CDM}$ website, at http://cdm.unfccc.int/Statistics/Issuance/CERsIssuedByHostPartyPieChart.html India hosts 20 per cent. India's and the PRC's share of the number of projects is similar, at http://cdm.unfccc.int/Statistics/Registration/AmountOfReductRegisteredProjPieChart.html.

92 And other 'Kyoto units' relating to other parts of the KP.

93 The standard chemical formula for the HFCs is $\mathrm{CEF}_{3}$, and their standard name in chemistry is trifluoromethane. $\mathrm{HFC}_{23}$ is a trade name.

${ }^{94}$ IPCC, Safeguarding the Ozone Layer and the Global Climate System (Cambridge: Cambridge University Press, 2006).

95 P. Castro and A. Michaelowa, Empirical Analysis of Performance of CDM Projects (London: Climate Strategies, 2008), fig 1, at http://www.climatestrategies.org/our-reports/category/39/138.html.

${ }_{96}$ This is the figure given in M. Wara, 'Is the Global Carbon Market Working' (2007) 445(7128) Nature 594. It is, of course, highly speculative as it is dependent on the market price of CERs generally, and one can find much larger estimates of it in the literature.

97 ibid. See further M. Wara, 'Measuring the Clean Development Mechanism's Performance and Potential' (2007-2008) 55 UCLA Law Review 1759.

98 There is, of course, no empirical evidence of the long-term GWP of these gasses, and the construction of GWP data is a complex and speculative matter which is brilliantly discussed in D. Mackenzie, 'Making Things the Same: Gasses, Emissions Rights and the Politics of Carbon Markets' (2009) 34 Accounting, Organisations and Society 440. The IPCC has since revalued the GWP of $\mathrm{HFC}_{23}$ to 14,800 . 
happens, the scrubbing of $\mathrm{HFC}_{23}$ from refrigerant gas production plants is technologically simple and cheap, and is now perfectly routine in refrigerant gas production in Annex 1 countries. The consequence both of this fact and the enormous GWP rating of $\mathrm{HFC}_{23}$ has been a huge growth in refrigerant gas production in the PRC, unarguably in pursuit of the CERs, which are a far greater source of profit than actual refrigerant gas production. This outrageous situation was brought to wide attention by Michael Wara and his colleagues in the Stanford Program on Energy and Sustainable Development, on whose work we have drawn heavily. Wara tells us that 'refrigerant manufacturers were transformed overnight by the CDM into ventures that generated large volumes of CERs, with a sideline in the manufacture of industrial gasses'. ${ }^{99}$

Attempts have been made, and persist, ${ }^{100}$ to explain the concentration on $\mathrm{HFC}_{23}$ mitigation as an instance of project developers first picking the low hanging fruit' offered by the cheapness of $\mathrm{HFC}_{23}$ mitigation. But it is of the nature of the attractiveness of low hanging fruit that it encourages attempts to grow more of it, and this is exactly what happened in this episode. Responses to this particular problem are, of course, possible, and the CDMEB now takes a very strict line towards $\mathrm{HFC}_{23}$ proposals, with such CER issuance for this as continues largely being a matter of things working through the pipeline. More generally, the IPCC's inclusion of the HFCs in the Annex B list of GHGs, especially with the GWP rating given to $\mathrm{HFC}_{23}$, now seems like a mistake, ${ }^{101}$ and the target set for almost complete elimination of $\mathrm{HFC}_{22}$ production in developing countries under the Montreal Protocol has been brought forward to 2030, with this elimination now being financed by, in effect, direct, targeted subsidy from Annex I parties.

But for future projects not to give rise to similar problems, future regulation must prevent the perverse incentive that gave rise to the $\mathrm{HFC}_{23}$ episode occurring again, and attempts to do this have failed, with the result that the problem has been reproduced. PRC $\mathrm{HFC}_{23}$ mitigation has been replaced by PRC hydro-electric power generation as the preponderant CDM activity. On its face this seems a move in the right direction, and the magnitude and technological difficulty of many of these projects, which could hardly be more different to the easy process of $\mathrm{HFC}_{23}$ scrubbing, cannot present a similar invitation to develop projects just for

\footnotetext{
99 M.W. Wara and D.G. Victor, A Realistic Policy on International Carbon Offsets (Working Paper 74, Programme on Energy and Sustainable Development, Stanford University, April 2008).

${ }^{100}$ UNEP, 'Action on HFC Gases "Low Hanging Fruit" Opportunity to Combat Climate Change Says UN Environment Chief' (Press Release, 22 June 2009), at

http://www.unep.org/Documents.Multilingual/Default.asp?DocumentID=589\&ArticleID=6227\&l=en. This press release reports the response of Mr Achim Steiner, UN Under-Secretary General and UNEP Executive Director, to a scientific paper confirming the enormous projected growth in developing country emissions of HFCs and the cheapness of eliminating HFC emissions. G.J.M. Velder, 'The Large Contribution of Projected HFC Emissions to Future Climate Forcing' (7 July 2009) 106(27) Proceedings of the National Academy of Science of the USA 10949. The scientific paper makes no reference whatsoever to the regulatory problems, of which its authors no doubt are wholly ignorant, and, unfortunately typically, neither does Mr Steiner.

${ }^{101}$ S. Barrett, 'Climate Treaties and the Imperative of Enforcement' in Helm and Hepburn, n 32 above.
} 
the CERs they will generate. But, as Wara and his colleagues have shown, ${ }^{102}$ what has happened is no less problematic.

Hydro-electric power installation could represent an emissions reduction only if it replaced projected growth in, say, coal-fired generation. But such is the immensity of the PRC's growth plans that to maintain that this is happening is completely implausible, and it is most disturbing that this has not prevented the issuance of CERs for the PRC's extremely ambitious hydro-electric power generation plans. Despite being by far the world's largest coal producer (more than double the USA), the PRC is now a major net coal importer, with imports growing at the astronomical rates (170 per cent in 2009) one associates with PRC growth statistics. It is impossible that, under these circumstances, the PRC would not seek to diversify power generation away from coal, and develop hydro-electric and coal-fired generation simultaneously. Though it is of the nature of the situation to which we are trying to direct attention that no data in which one can place real confidence will ever emerge, it is almost certain that none whatsoever of the CERs issued for PRC hydro-electric power generation represent actual emissions reductions, and entirely possible that CDM has actually expanded PRC GHG emissions through power generation overall.

In light of these two major failures, the claimed success of the CDM in terms of the growth of CER issuance up to the end of the FCP is illusory in terms of its intended environmental impact. There has been a tremendous growth in activity, but that activity cannot contribute to global emissions reduction, and very well may not have substantially contributed to emissions reductions even within nonAnnex 1 countries. It is likely that it has increased them, and we strongly suspect that it has. The available evidence would appear to lead to conclusions of essentially the same nature in respect of projects in other hosts, including India, ${ }^{103}$ and Brasil. ${ }^{104}$ It is beyond dispute that the CDM has been subject to a very serious regulatory failure of its 'environmental integrity', and to the analysis of this we now turn.

\footnotetext{
102 Activist criticism of hydro-electric projects also has been very telling: eg B. Haya, Failed Mechanism: How the CDM is Subsidising Hydro Developers and Harming the Kyoto Protocol (International Rivers Report, November 2007), at http://www.internationalrivers.org/files/Failed_Mechanism_3.pdf.

103 P. Castro and G. Bedecke, Empirical Analysis of Performance of CDM Projects: Case Study India (Climate Strategies Discussion Paper CDM-7, February 2008), at http://www.climatestrategies.org/ourreports/category/39/168.html.

${ }^{104}$ L. Fribirg and P. Castro, Empirical Analysis of Performance of CDM Projects: Case Study Brasil (Climate Strategies Discussion Paper CDM-8, February 2008), at http://www.climatestrategies.org/ourreports/category/39/166.html.
} 


\section{SOME MOST UNCOMFORTABLE LESSONS}

Whilst this is now being written with the advantage of hindsight, it was pointed out at the time of the establishment of the $\mathrm{CDM},{ }^{105}$ that something of the nature of the $\mathrm{HFC}_{23}$ episode would take place, though the extraordinary size of the problem posed by a single, relatively unimportant gas was not foreseen, ${ }^{106}$ certainly not by those who included $\mathrm{HFC}_{23}$ in Annex B.

The fundamental problem is that, though any development project can and will lead to action which runs counter to the project's aims, the CDM gives an extremely wide invitation to such action, and there is a serious limit about what can be done about this. The measuring of emissions, and therefore of reductions, is itself a highly vexed process, ${ }^{107}$ but at least 'emissions reduction verification' under the CDM can have reference to a claimed physical output. In contrast, 'project validation' by the CDMEB is a purely theoretical process entirely dependent on the establishment of a baseline which is a forecast of a state of affairs which it is intended will never come about. ${ }^{108}$ The methodology of all costbenefit analysis is open to criticism of the robustness of the identification of benefits, but the counterfactual baseline of carbon projects is speculative in a way which must exaggerate this difficulty, and therefore, by its nature, the CDM approvals process is fundamentally fragile, and readily open to opportunistic manipulation. ${ }^{109}$ As such, this process is extremely dependent on the integrity of the participants which, from the perspective of regulatory design, is a matter of correctly aligning incentives. Unfortunately, the conclusion we draw from our analysis is that the CDM is, in the jargon of institutional economics, an incentive incompatible design, ${ }^{110}$ creating immense moral hazard. ${ }^{111}$ As these points have been made in outline by numerous previous commentators, ${ }^{112}$ we can be brief.

There is an obvious incentive for those in non-Annex I countries who will receive monetizable CERs to make 'false' or 'phantom reductions', and an equally obvious incentive for their national authorities to approve these 'hot air' reductions to almost costlessly increase foreign investment and facilitate growth in

\footnotetext{
105 D. Victor, The Collapse of the Kyoto Protocol and the Struggle to Slow Global Warming (Princeton: Princeton University Press, 2001), 62.

106 A major World Bank study of the operation of the CDM in the PRC published in 2004 did not include $\mathrm{HFC}_{23}$ in any of its case studies: World Bank, Clean Development Mechanism in China (Washington DC: World Bank, 2nd ed, September 2004).

${ }^{107}$ E. Nisbet, et al, 'Issues in Establishing in situ Greenhouse Gas Monitoring Networks in Europe and in Regions of Interest to Europe' in H. Dolman, et al (eds), Ecological Studies, Vol 203: The Continental-Scale Greenhouse Gas Balance of Europe (Berlin: Springer, 2008), 91.

${ }^{108}$ C. Zhang, et al, 'Carbon Intensity of Electricity Generation and CDM Baseline: Case Studies of Three Chinese Provinces' (2005) 33 Energy Policy 451.

109 A. Michaelowa and P. Purohit, Additionality Determination of Indian CDM Projects: Can Indian CDM Project Developers Outwit the CDM Executive Board? (Climate Strategies Discussion Paper CDM-1, 1 February 2007), at http://www.climatestrategies.org/our-reports/category/39/162.html.

110 L. Hurwicz, 'On Informationally Decentralised Systems' in C.B. McGuire and R. Radner (eds), Decision and Organisation (Amsterdam: North-Holland, 1972), 320.

111 M.V. Pauly, 'The Economics of Moral Hazard' (1968) 58 American Economic Review 531.

112 eg E. Woerdman, The Institutional Economics of Market-based Climate Policy (Amsterdam: Elsevier, 2004).
} 
their economies. ${ }^{113}$ It is to counter this moral hazard that CDMEB methodology, approval and monitoring seek to ensure 'additionality' in the sense that a carbon project must secure reductions in addition to any reductions which would, without CDM funding, have taken place. Additionality is, indeed, the whole point of the CDM. But, other than that provided by compliance with the formal requirements of the CDM project validation process, we can see no incentive which the CDM provides to non-Annex I parties to respect additionality. The incentive it provides is aligned in quite the opposite direction, and we can see no effective countervailing tendency. The PRC evidence we have reviewed shows this to be no merely theoretical concern. It is the explanation of most CDM activity. It must be said that the non-Annex I parties, including the PRC, are countries in which a lack of integrity of governance, including outright corruption, have been identified as major obstacles to obtaining welfare-enhancing returns to investment in other development projects. ${ }^{114}$ In our opinion, carbon projects will tend to be subject to immense moral hazard as they are of a nature which gives a wide invitation to this and are to take place in environments where such invitations are widely known to be taken. ${ }^{115}$

In light of what has happened so far, COP15 decided to continue with a review of 'capacity building'116 in host countries, ${ }^{117}$ begun in $2004 .{ }^{118}$ Capacity

113 Wara, $\mathrm{n} 97$ above, tells us that CER income from $\mathrm{HFC}_{23}$ reduction is taxed by the PRC government at 65 per cent. CDM activity generally in the PRC has, unsurprisingly, been marked by a very high degree of government involvement: K. Tangen and G. Heggelund, 'Will the Clean Development Mechanism be Effectively Implemented in China?' (2003) 3 Climate Policy 303. On the place of national authorities in the CDM architecture, see text accompanying n 131 below. Any moral sanction inhibiting the making of non-additional proposals will be weakened to the extent that phantom reductions may be seen as a wealth transfer from developed to developing countries which it is only right should take place anyway, which is the atmosphere of everything that has happened under the UNFCCC.

114 Brazil, India, and the PRC are respectively 75, 84, and 79 on Transparency International's Corruption Perceptions Index 2009. 180 countries are ranked with the least corrupt at 1, at http://www.transparency.org/policy_research/surveys_indices/cpi/2009/cpi_2009_table.

115 W.D. Nordhaus, 'Economic Analyses of the Kyoto Protocol: Is There Life After Kyoto?' in E. Zedillo (ed), Global Warming: Looking Beyond Kyoto (New Haven: Center for the Study of Globalisation, Yale University, 2008), 91, 98. In the development literature, the situation in which what should be the beneficent presence of natural resources so leads to the exploitation of those resources in ways which actually diminish welfare has been described as the 'resource curse'. R. Torvik, 'Natural Resources, Rent Seeking and Welfare' (2002) 67 Journal of Development Economics 455. The commodification of potential GHG emissions in countries which are actually developing represents, in this sense, the creation of an enormous 'natural resource'.

116 COP15, Draft Decision: Capacity Building Under the Convention; and CMP5, Draft Decision: Capacity Building Under the Kyoto Protocol, at http://unfccc.int/meetings/cop_15/items/5257.php.

117 Of course, one should not ignore compliance issues in the Annex 1 countries. A striking US example is the perverse incentive offered by a tax credit intended to promote the use of biofuel which has led to the addition of fossil fuel to a major method of major wood pulp production formerly more or less entirely based on biofuel. C. Hayes, 'Pulp Nonfiction' The Nation (20 April 2009), at http://www.thenation.com/doc/20090420/hayes; and B. Ivry and C. Donville, 'Black Liquor Tax Boondoggle May Net Billions for Papermakers' Bloomberg.com (17 April 2009), at

http://www.bloomberg.com/apps/news?pid=20601109\&sid=abDjfGgdumh4. This would be hilarious were it not for the cost, running into USD billions, and the consequent disruption of the wood pulp industry, which has led to an international trade dispute. There also has been a remarkable growth in $\mathrm{HFC}_{23}$ activity under the EUETS which we are currently investigating: EEA, Greenhouse Gas Emission Trends and Projections in Europe 2009 (Copenhagen: EEA, 2009), sec 2.3. 
building was mentioned in UNFCCC, art 9, and KP, art 10(e), but was at all seriously addressed only in the Marrakesh Accords agreed in 2001 at COP7,,19 which the IPCC claims gave 'detailed rules for the implementation of the Protocol'. ${ }^{120}$ This claim is exaggerated in all respects, ${ }^{121}$ and, though a Compliance Committee was (tellingly belatedly, the last of the KP institutions) created in March 2006,122 its 'enforcement branch' has no jurisdiction over non-Annex 1 countries, which have, of course, no concrete KP reductions obligations, and one has to say that what was said then and is being said now of capacity building is so vague and general that it is better regarded as the recognition of necessary work rather than to any plausible statement of how the work might be carried out.

Very worryingly, the CDM also gives the Annex 1 purchasers of CERs an incentive towards trading in phantom reductions, so that they will not operate as a countervailing force to the non-Annex 1 sellers. If one assumes (against the evidence) that the governments of the Annex I parties impose a cap which actually is a biting constraint on emissions, then the purchase of CERs allows the effective relaxation of that cap by offsetting CERs against domestic reduction targets. This the way the CDM is meant to work. So far, despite its failure to reduce its domestic emissions in line with its FCP targets that we have noted, the EU and the UK has been able publicly to claim to be somewhere near their FCP targets, ${ }^{123}$ because inter alia offsets have distorted reported emissions reductions in a way that is not transparent. ${ }^{124}$ In our opinion, were the practices common in EU and UK official reporting on this issue to take place in a commercial context such as the issuance of a company prospectus, they would amount to fraudulent misrepresentation.

In recognition of this, just as additionality is meant to be central to the operation of the CDM in non-Annex I parties, so 'supplementarity' is meant to be

118 COP10, Report of the Conference of the Parties on its Tenth Session, Held at Buenos Aires from 6 to 18 December 2004 (FCCC/CP/2004/10/Add.1, Decision 2/CP/10), at

http://unfccc.int/resource/docs/cop10/10a01.pdf.

119 COP7, Report of the Conference of the Parties on its Seventh Session, Held at Marrakesh from 29 October to 10 November 2001 (FCCC/CP/2001/13/Add.1-4, Decision 2/CP7), at

http://unfccc.int/resource/docs/cop7/13a01.pdf.

120 UNFCC website, at http://unfccc.int/kyoto_protocol/items/2830.php.

121 eg P.G. Harris, 'Europe and the Politics and Foreign Policy of Global Climate Change' in P.G. Harris (ed), Europe and Global Climate Change (Cheltenham: Edward Elgar, 2007), 3, 13, describes the Marrakesh Accords as 'a complicated mix of measures for implementing the [KP], largely designed to gain ratification from enough states to allow the $[\mathrm{KP}]$ to enter into force'.

122 UNFCCC Secretariat, 'Groundbreaking Kyoto Protocol Compliance System Launched' (Press Release, 3 March 2006), at

http://unfccc.int/files/press/news_room/press_releases_and_advisories/application/pdf/20060303_co mpliance_committee_1st_meeting.pdf. A schematic representation of 'the compliance system' is available at http://unfccc.int/files/kyoto_mechanisms/compliance/application/pdf/comp_schematic.pdf.

${ }^{123}$ EEA, n 117 above, fig 2.4. In addition to including offsets, this graph excludes aircraft, shipping, and certain other emissions.

124 ibid, 12: 'In 2009 the progress of EU-15 Member States towards their targets was assessed, for the first time, by focusing on projections of their non-ETS emissions.' The general problem is commendably (but in our opinion most inadequately) addressed in Environmental Audit Committee, Eighth Report: Emissions Trading: Government Response to the Committee's Second Report of Session 2006-07 on the EU ETS (2006-2007) (HC 1072). 
central to its operation in Annex I parties. The use of CERs is meant to be limited so that offsetting is essentially supplementary to domestic reductions, which still have to be made. But it is obvious that supplementarity is quite in contradiction to the entire way the CDM is to work. Offsetting is the source of CDM finance. Eliminating it would eliminate that finance. Despite its adoption by, for example, the UK, ${ }^{125}$ supplementarity can hardly be said to be a policy at all. It is rather a statement of a pious wish that runs counter to the basic aim of the CDM and of those trading in CERs in both Annex I and non-Annex I countries.

In sum, project developers in host countries and purchasers in Annex 1 countries are both aligned against a third party, the taxpayer, and consumer in Annex 1 countries, from whom CDM finance ultimately is derived, creating a classic 'rent-seeking' system. ${ }^{126}$ It is of much less importance than this fundamentally foolish alignment of incentives, but carbon project design under the CDM allows great opportunities for collusion between the operator of the installation that will generate the CERs and the purchaser of those CERs. Although 'unilateral CDM', in which a potential emitter in a non-Annex I country unilaterally registers a project, the CERs of which it will eventually offer for sale, is possible, ${ }^{127}$ it runs against the grain of the CDM and so far it is rare. As was envisaged in the technology transfer element of the CDM, the standard project is the result of the purchaser of the CERs entering into cooperation with their generator, the former bringing its finance and technological capacity to bear from the outset, and generating the project design as a result. In this relationship, respect for additionality and supplementarity simply runs counter to the reason the relationship exists.

All this, of course, places an immense burden on the CDM approvals process, and therefore on the CDMEB. Though it makes final approvals, that process was bound to become extremely burdensome if the CDM was any sort of a success, and an implausibly immense bureaucracy would be needed if the CDMEB was itself to carry out approvals. The approvals process has been delegated to subsidiary regulatory bodies which the CDMEB accredits called 'Designated Operational Entities' (DOE). These currently are 25 private sector companies, ${ }^{128}$ which have taken up the role of DOEs with the aim of promoting carbon trading, their profitability being directly proportional to its success. These companies describe a range from long-established, reputable validation organisations to newly incorporated companies, ${ }^{129}$ but it is obviously extremely hazardous to place bodies with such obvious conflicts of interest in these vital monitoring roles. We feel

\footnotetext{
125 Climate Change Act 2008, sec 11.

126 A.O. Kreuger, 'The Political Economy of the Rent-seeking Society' (1974) 64 American Economic Review 291.

127 CDMEB, Eighteenth Meeting Report (CDM-EB-18, 25 February 2005), para 57, at

http://cdm.unfccc.int/EB/018/eb18rep.pdf

128 CDM website, at http://cdm.unfccc.int/DOE/list/index.html.

${ }^{129}$ But see n 130 below.
} 
ourselves to be falling into repetition when we say that it comes as no surprise that, in the more suspicious climate in which it now feels itself to operate after criticisms such as Wara's received public attention, the CDMEB has had temporarily to suspend two of the 'big three' DOEs responsible for the great majority of CERs issued so far. ${ }^{130}$

The 'Designated National Authorities' (DNAs) which the parties to the KP must establish to participate in the CDM were initially intended to play a background role, giving formal initial authorisation to and registering project activities essentially for the purposes of data gathering and policy formulation, and providing public support for those activities. ${ }^{131}$ In the more suspicious climate we have mentioned, the UNFCCC Secretariat and the CDMEB envisage a much more active role for DNAs in the 'scaling up' of the CDM now generally thought to be urgent. In particular, 'sectoral trading', in which DNAs actively plan for reductions below caps in sectors they identify, has been advocated. ${ }^{132}$ Although sectoral trading is to be motivated by sale of unused allowances on the international emissions market, it is in effect a move back towards command and control which effectively acknowledges the failure of market-mimicking. It therefore is implausible for the reasons which led UNFCCC to adopt the KP flexibility mechanisms in the first place. ${ }^{133}$

The CDMEB, set up under art 12 of the Marrakesh Accords, is a 10-member supervisory panel which may appoint such committees, working groups, etc as it sees fit to help it in its supervisory role, but which has the principal function of approving the methodologies of project design and appointing and monitoring DOEs. In a very rare show of agreement in this vexed area, the CDMEB itself is universally acknowledged to have been extremely under-resourced when

130 'UN Suspends One of the "Big Three" CDM Auditors' European Daily Carbon Markets (14 September 2009). European Daily Carbon Markets is the market newsletter of ICIS Heren, a reputable energy market intelligence service. Very considerable effort researching the UNFCCC databases has so far failed to shed light on the detail of these suspensions, other than that they were not of recently formed companies but of the number we have described as long-established and reputable.

131 A list of DNAs is available at the CDM website, at http://cdm.unfccc.int/DNA/index.html. The entry for the UK is out of date. DECC is the UK DNA, at

http://www.decc.gov.uk/en/content/cms/what_we_do/change_energy/tackling_clima/intl_strat/mech anisms/clean_developm/clean_developm.aspx. DECC has set up a non-profit company, the Carbon Trust, as a 'delivery partner' with 'the mission to accelerate the move to a low carbon economy', at http://www.carbontrust.co.uk/about-carbon-trust/pages/default.aspx.

132 M. Lazarowicz, Global Carbon Trading (London: The Stationery Office, 2009), sec 6.3. This report, commissioned by the former Prime Minister, was the leading document on the former government's longer-term thinking on climate change policy.

133 The case for a carbon tax is sound insofar as it rests on an exposure of the shortcomings of KP emissions trading, but it is telling that it is this, rather than any argument that a tax is plausible, that plays the greater part in the most influential statements of that case. The point is clear in W.D. Nordhaus, $A$ Question of Balance (New Haven: Yale University Press, 2008), ch 8, but even more clear in R.N. Cooper, 'Towards a Real Global Warming Treaty' (1998) 77(2) Foreign Affairs 66; 'Alternatives to Kyoto: The Case for a Carbon Tax' in J. Aldy and R.L. Stavins (eds), Architectures for Agreement (Cambridge: Cambridge University Press, 2007), ch 3.1. We want, without argument, to say that we agree with the claim that the $\mathrm{KP}$ had no chance of being concluded had it sought to implement a biting global carbon tax regime; indeed, agreeing trading mechanisms which would have initially involved biting emissions reductions without extensive flexibility would have been impossible for the same reasons. M. Grubb, et al, The Kyoto Protocol (London: Royal Institute of International Affairs, 1999), sec 3.7. 
established, and this has rightly been regarded as contributing to governance failures which it is now recognised must be addressed. ${ }^{134}$ But, on the other hand, the CDMEB has been continually beset by extensive, justified complaints about the unarguably unacceptable length of the project pipeline caused by the time taken to secure approval, and though the resourcing of the CDMEB is being addressed, these complaints must persist, and surely grow enormously larger whatever the resource allocated if the CDM is to substantially contribute to emissions reductions in line with the two degrees Celsius target, even if the bulk of the work can be delegated to DOEs. The size of the CDM reductions which must be secured pose, to our mind, an impossibly demanding organisational task for the CDMEB.

\section{THE IRRATIONALITY OF THE KP}

The conclusion we draw from this description and analysis of the structure and operation of the CDM is that it never has had, nor does it have now, any prospect whatsoever of working in the sense of securing GHG emissions reductions in line with the targets which have been set to avoid DAI, including the two degrees Celsius target. And, in our view, this is the inevitable result of the structure of the $\mathrm{KP}$. We hope we have shown that the KP embodies a mistaken policy. But it is not enough to say that it is mistaken. We must recognise that it is not rational. ${ }^{135} \mathrm{It}$ is necessary for an emissions reduction policy of the 'top down' nature of the $\mathrm{KP}$ to disaggregate any global emissions reduction target into individual targets for responsible authorities, in essence countries which, combined, are to meet the overall target. Because of the technologically global nature of the problem, these targets are mutually dependent, ${ }^{136}$ and, in the continuing absence of targets for non-Annex I countries, and with it not being possible to have confidence in the

\footnotetext{
${ }_{134}$ COP15, Draft Decision: Further Guidance Relating to the Clean Development Mechanism, paras 6-43, at http://unfccc.int/files/meetings/cop_15/application/pdf/cmp5_cdm_auv.pdf.

135 R.S.J. Tol, 'Kyoto, Efficieny and Cost-Effectiveness' (1999) 20 Energy Journal Special Issue 131, 153.

136 Nordhaus has done the most to examine this in the context of the varying burdens which would have to be born given differing levels of participation. Nordhaus, n 133 above; 'The Impact of Treaty Nonparticipation on the Costs of Slowing Global Warming' (2009) 30 Energy Journal Special Issue 2, 39. Of course, one can have no more reason to believe the participation data Nordhaus needs for his modelling would ever be available whether policy is based on the KP or on his carbon tax regime, for this regime would be beset by implementation problems as much as the KP, a point about which Nordhaus is, in fact, equivocal. R.P. Murphy, 'Rolling the DICE: William Nordhaus's Dubious Case for a Carbon Tax' (2009) 14 The Independent Review 197 (DICE is the Dynamic Intergrated Model of Climate and Economy, one of the models used in the macro-economics of climate change). In particular, an elementary study of current international taxation shows that no country will ever be in or out of the tax regime in the way Nordhaus' modelling requires.
} 
implementation of the CDM (and therefore any global carbon market), ${ }^{137}$ there is no rational way in which any individual targets can be set.

In these circumstances, the typical policy has been to set caps or other targets which are as ambitious as it is politically possible to set in the two beliefs that any progress towards emissions reduction as may result will be of value, and that, the greater the pressure created by the cap, the more the market will be stimulated into action. But action in pursuit of the impossible is irrational, and great costs are being imposed on those Annex 1 economies which are implementing policies related to carbon trading in return for no progress on any KP target. The UK's policy under the Climate Change 2008 is a most pronounced example of this, for it sets sectoral targets which, if taken literally to mean concrete reductions in domestic emissions, require rates of 'decarbonisation' of the national economy which it has plausibly been argued are impossibly costly to achieve. ${ }^{138}$ Nevertheless, that what is being pursued is impossible does not mean that immense costs may not be run up in the course of the doomed effort. ${ }^{139}$

The incurring of great costs under the 2008 Act in the conditions established by the KP cannot be subject to the cost-benefit calculations which have been the basis of the assessment of national welfare economic intervention. As the costs of climate change mitigation for each country cannot be known because of the inability to control emissions from the non-Annex 1 countries, there can be no welfare gain in terms of KP goals from observing Annex 1 domestic caps, and the costs of such observance theoretically can grow to infinity in a doomed attempt to counter their fruitlessness. ${ }^{140}$ The practical political and economic limits to the

${ }^{137}$ In relationship to EU policy, see J. Scott, 'The Multi-Level Governance of Climate Change' in P. Craig and G. de Burca (eds), The Evolution of EU Law (Oxford: Oxford University Press, forthcoming). We are grateful to Professor Scott for showing us this work in draft.

138 R.A. Pielke, Jr, 'The British Climate Change Act: A Critical Evaluation and Proposed Alternative Approach' (2009) 4 Environmental Research Letters 1 . Though we have benefitted from his exposition of this Act, which highlights its many difficulties, we find Professor Stallworthy to be too sanguine about its prospects of success: M. Stallworthy, 'Legislating Against Climate Change: A UK Perspective on a Sisyphean Challenge' (2009) 72 Modern Law Review 412.

${ }_{139}$ For the reasons we are setting out, the KP commits any Annex-1 country that takes its emissions reduction responsibility seriously to an obligation to do so regardless of a cost which effectively is unbounded, in essence 'an open-ended surrender of a potentially important part of their sovereignty'. W.J. McKibbon and P.J. Wilcoxen, Climate Change Policy After Kyoto (Washington DC: Brookings Institution, 2002), 53. This obviously is a good reason for any Annex 1 Government which considers its national interest not to undertake that responsibility, or to do so only in a way which undermines the possibility of meeting the targets, and this is more or less what has happened with the CA.

${ }^{140}$ Leaving aside the more direct costs, to the extent that a country does manage to affect the pricing of its products so that it does include a shadow cost for carbon, this will lower its international competitiveness against countries which do not do this. The SR, ch 111 takes a sanguine view of this 'competiveness threat', though this seems to us to be a major issue. The evaluation of the problem in the Australian Garnaut Review seems to us to be much more realistic. R. Garnaut, The Garnaut Climate Change Review (Cambridge: Cambridge University Press, 2008), ch 14. At a further stage of the analysis, it can be predicted that, to the extent that the competitiveness threat leads to a relocation of production from an Annex I country to a non-Annex I country, but the relocated output is then exported to the Annex I country, then the consequent reduction in the Annex I country's emissions is completely illusory. The emissions now take place in the exporting country, and to them is added the emissions represented by transport and associated costs. This is one implication of the activist critique of 'embodied carbon' in the calculation of Annex I country emissions: eg J. Kegun, et al, Embodied Carbon in Traded Goods (Winnipeg: International Institute for Sustainable Development, 2008), at 
pursuit of KP goals are the ultimate willingness of taxpayers and consumers in Annex I countries to fund the policies which cannot even identify, let alone secure, necessary emissions reductions, but the emissions reduction policy itself cannot be subjected to rational cost-benefit calculation. It is not irrational to argue that one should ignore some non-Annex 1 countries' emissions as being too small to effect global policy. But, of course, it is irrational not to include the emissions of the PRC, for this removes the cap on the global system. In sum, in Weber's terms, commitment to the KP, rather than being instrumentally rational, is value rational: 'that is, determined by a conscious belief in the value for its own sake or some ethical, aesthetic, religious, or other form of behaviour, independently of its prospects of success'.141

\section{CONCLUSION: THE APPOINTMENT OF THE NEW EXECUTIVE SECRETARY OF THE UNFCCC SECRETARIAT}

The widespread criticism of the KP as a 'political' regulation is generally tedious and ineffective, for what important regulatory measure is not a political compromise? Nor can it be said that regulatory measures of any importance ever have full control of the conditions of their being effective. But the new global welfare economics of the KP nevertheless is a regulatory regime which is political in an unacceptable sense because, as it has no control whatsoever over the basic condition of its success, and, as that condition does not and will not obtain, it can proceed only by a disregard of cost-effectiveness which is not economically rational but is an act of will, and, in the absence of this rationality, this policy is not accountable, for what counts as a good performance? It was the dawning realisation of this at COP15, at which the non-Annex 1 emitters stated their firm intention never to comply with the KP, subsequently cost the former Executive Secretary of the UNFCCC Secretariat his post.

His replacement is the perfect appointment. ${ }^{142}$ Ms Christiana Figueres, a distinguished Costa Rican public servant, had been a member of the Costa Rican UNFCCC negotiating team since 1995 and had served on many international environmental and climate change bodies. ${ }^{143}$ She has made extensive suggestions for reform of the CDM. ${ }^{144}$ The failure of the KP will come as no surprise to her, as she has never been particularly concerned about the success of the KP judged

http:/ /ictsd.org/i/publications/67904/?view=document.

141 M. Weber, Economy and Society (Berkeley, University of California Press, 1968), 24-25.

142 UNFCC, 'Christiana Figueres Appointed New UNFCCC Executive Secretary' (Press Release, 17 May 2010), at

http://unfccc.int/files/press/news_room/press_releases_and_advisories/application/pdf/100517_press

rel_new_es.pdf.

143 http://www.figueresonline.com/index.htm.

144 http://www.figueresonline.com/design.htm. 
against the target it publicly set itself of effectively preventing DAI. In 2007, reviewing what already seemed very disappointing evidence about meeting that target, she told us that:

the [...] KP was never meant as the solution to climate change, nor its market mechanisms intended as a final product. The KP is limited in its global emission reduction target, in its time frame, and in the countries that participate. Given the scale of the climate challenge, the KP can only be seen as the preamble of an extended and enhanced effort, which should continue to rely heavily on market mechanisms in order to manage the costs. ${ }^{145}$

The KP and the new global welfare economics already have reached a point of crisis. If one takes the KP to be designed to avoid DAI, it has been from the outset bound to fail, and it is now being seen to be failing. Assessed in terms of rational economics and broadly democratic policymaking, it should be abandoned. But, of course, this assumes some conventional form of accountability, and the appointment of Ms Figueres illustrates that there is a different type of policymaking at work in the new global welfare economics, in which a vanguard congnoscenti see their role to be to lead those '[e]ntrenched in their traditional defensive positions'146 to positions the virtue of which they are incapable of identifying for themselves. Ms Figueres embodies, in our opinion, the unacceptably manipulative attitude to regulation which is characteristic of this congoscenti, to whom the KP was only ever a device to encourage the right sort of attitude to global warming, and the KP's complete revision, amounting to the abandonment of its recognisable form, can now be undertaken in a sanguine frame of mind unhindered by the concern with accountability, economy, and efficacy which informs this paper. Remaining certain that '[t]oday's wisdom demands higher emission reduction levels than those made possible through the current $[. .$.$] CDM', Ms Figueres will now change the basic 'logic' of the KP, which$ she has long thought obsolete. Her complete disregard of the immense expenditure wasted already in pursuit of a goal which cannot be achieved may be continued because, from her political perspective, all that is now needed is the creation of 'a new world order' in which the developing countries, instead of posing an intractable problem, will be part of the 'solutions group'. ${ }^{147}$

That the UN is leading the formulation of a 'policy' of 'saving the planet'148 by establishing a 'new world order' which will bring about 'a wholesale reconfiguration of global industry' by means of a 'second industrial revolution' opens up an infinite vista of waste. Nevertheless, at some point in the medium term, the CDM and the KP will be abandoned. The issue is the way this

145 Figueres and Newcombe, n 20 above, 1.

146 C. Figueres and C. Streck, 'The Evolution of the CDM in a Post-2012 Climate Agreement' (2009) 18

The Journal of Environment and Development 227, 234.

147 ibid, 234, 243

148 UNDESA, n 31 above. 
abandonment will be understood, as either the rejection of a policy leading to government failure at an unprecedented scope and scale, or a part of a process of global welfare economic policy formation which proceeds by being decoupled from rational criteria of assessment. We place our hope in Coase's belief that ' $[t]$ he demand for nonsense seems to be subject to the universal law of demand: we demand less of it when the price is higher'. ${ }^{149}$

149 R.H. Coase, 'Economists and Public Policy' in R.H. Coase, Essays on Economics and Economists (Chicago: University of Chicago Press, 1994), 47, 55. 


\section{LIST OF ACRONYMS}

The following acronyms are used in these notes:

BRIC: Brasil, Russia, India, China bloc

CA: Copenhagen Accord

CCC: UK Committee on Climate Change

CDM: Clean Development Mechanism

CDMEB: Clean Development Mechanism Executive Board

CER: Certified Emissions Reduction

COP1, COP2, etc: see n 2 above

DAI: dangerous anthropogenic interference

DECC: UK Department of Environment and Climate Change

EC: European Commission

EEA: European Environment Agency

EU: European Union

EUETS: European Union Emissions Trading System

FCP: First Commitment Period

GHG: greenhouse gas

GWP: global warming potential

HFC: see $\mathrm{n} 93$ above and associated text

IPCC: Intergovernmental Panel on Climate Change

KP: Kyoto Protocol

PRC: People's Republic of China

SR: Stern Review

UK: United Kingdom

UN: United Nations

UNDESA: United Nations Department of Economic and Social Affairs

UNDP: United Nations Development Programme

UNEP: United Nations Environment Programme

UNFCCC: United Nations Framework Convention on Climate Change

USA: United States of America 